\title{
Fabrication of Novel High Surface Area Mushroom Gilled Fibers and Their Effects on Human Adipose Derived Stem Cells Under Pulsatile Fluid Flow for Tissue Engineering Applications
}

Stephen A. Tuin ${ }^{1}$, Behnam Pourdeyhimi ${ }^{2}$, Elizabeth G. Loboa ${ }^{1,3,4}$

${ }^{1}$ Joint Department of Biomedical Engineering

at North Carolina State University

and the University of North Carolina at Chapel Hill

4208 EB3, Campus Box 7115

Raleigh, NC 27695-7115

USA

Phone: 303.946 .4873

Email: satuin@ncsu.edu

${ }^{2}$ The Nonwovens Institute

at North Carolina State University

College of Textiles

2401 Research Drive

Raleigh, NC 27695

USA

Email: bpourdey@ncsu.edu

${ }^{3}$ Department of Materials Science and Engineering

at North Carolina State University

EB 1, Room 3002

Raleigh, NC 27695

USA

Phone: 919.513 .4015

Fax: 919.513.3814

Email: egloboa@missouri.edu

${ }^{4}$ Elizabeth Loboa (Corresponding Author)

College of Engineering, Office of the Dean

W1051 Thomas \& Nell Lafferre Hall

Columbia, MO 65211

USA

Phone: 573.882 .4378

Fax: 573.882.2490

Email: egloboa@missouri.edu 


\section{Abstract}

The fabrication and characterization of novel high surface area hollow gilled fiber tissue engineering scaffolds via industrially relevant, scalable, repeatable, high speed, and economical nonwoven carding technology is described. Scaffolds were validated as tissue engineering scaffolds using human adipose derived stem cells (hASC) exposed to pulsatile fluid flow (PFF). The effects of fiber morphology on the proliferation and viability of hASC, as well as effects of varied magnitudes of shear stress applied via PFF on the expression of the early osteogenic gene marker runt related transcription factor 2 (RUNX2) were evaluated. Gilled fiber scaffolds led to a significant increase in proliferation of hASC after seven days in static culture, and exhibited fewer dead cells compared to pure PLA round fiber controls. Further, hASC-seeded scaffolds exposed to 3 and 6 dyne $/ \mathrm{cm}^{2}$ resulted in significantly increased mRNA expression of RUNX2 after one hour of PFF in the absence of soluble osteogenic induction factors. This is the first study to describe a method for the fabrication of high surface area gilled fibers and scaffolds. The scalable manufacturing process and potential fabrication across multiple nonwoven and woven platforms makes them promising candidates for a variety of applications that require high surface area fibrous materials.

Keywords: Gilled high surface area fibers, human adipose derived stem cells, pulsatile fluid slow, shear stress, scalable tissue engineering scaffolds 


\section{Introduction}

In this manuscript, we describe for the first time the fabrication of a novel fiber cross sectional morphology, which we have termed "gilled" fibers, for their resemblance to the underside of a mushroom cap. Gilled fibers consist of an outer solid poly(lactic acid) (PLA) shell, with multiple finger like PLA projections extending toward an internal hollow channel. Gilled fiber processing to fabricate carded nonwoven fabrics as scaffolds for tissue engineering applications is evaluated and discussed.

Tissue engineering strategies for the creation of new functional bone tissue using a stem cell source require recapitulation of the chemical and mechanical environment of the native tissue being replaced. It is well known that chemical cues are capable of regulating differentiation of a variety of stem cell sources. However, in the past few decades, we and others have shown the critical role of the mechanical environment in controlling stem cell fate [1-4], including tensile strain [5-10], shear stress [11-13], and hydrostatic pressure $[14,15]$. In the context of bone tissue engineering, compressive forces exerted on bones during normal day-to-day movement result in pressure driven flow of interstitial fluid through canaliculi, exposing mechanosensitive osteocytes to shear stress $[12,13,16-18]$. Compressive forces exerted on bones during normal day-to-day movement result in pressure driven flow of interstitial fluid through canaliculi, exposing osteocytes to shear stresses. Osteocytes have been shown to respond to these changes in shear stress and initiate an appropriate cellular response $[12,16,17]$. Bone tissue experiences shear stresses in the range of 8- 
30 dynes $/ \mathrm{cm}^{2}$ during normal physiological loading, with 30 dyne/cm2 representing peak loading during extensive physical activity [19].

As a result, researchers have investigated the use of biomimetic magnitudes of shear stress for functional bone tissue engineering applications using stem cells. Multiple studies have evaluated the impact of fluid shear stress, both pulsatile and oscillatory, on osteocytes $[12,13,17,18,20,21]$ and bone marrow derived mesenchymal stem cells (MSC) [21]. They have shown that shear stresses consistent with shear stresses that occur in bone during normal physiological loading increase osteogenesis and new bone formation $[12,13,17,18,20,21]$. Human adipose derived stem cells (hASC), a relatively more abundant and accessible stem cell source than MSC, have also been shown to be mechanosensitive to shear stress $[1,16,22]$. Human ASC are an attractive candidate for a variety of tissue engineering strategies due to their relative ease of harvest compared to MSC and other stem cell sources. Human ASC can be readily obtained from routine liposuction and abdominoplasty procedures. We and others have shown that hASC are capable of multipotent differentiation, including adipogenesis, osteogenesis, and chondrogenesis [9,14,23-31].

Shear stress has been shown to upregulate osteogenesis of ASC cultured on two dimensional substrates seeded with cells and exposed to pulsatile fluid flow (PFF) [11]. However, for the generation of three dimensional tissues, an initial biodegradable scaffolding structure is needed for early attachment of hASC, providing initial structural integrity, and capable of withstanding applied fluid flow. Our group and many others have reported on the use of poly(lactic 
acid) (PLA), an FDA-approved biodegradable polymer, for use in the creation of tissue engineering scaffolds [23,32-36]. The degradation rate of PLA can be tuned by altering the polymer properties, such as molecular weight and crystallinity, to achieve the desired rate of degradation for a particular application [37]. In this study, co-spinning of PLA using a specialized winged fiber spinnerette with AQ55S as a second, sacrificial polymer, facilitates the formation of the unique gilled fiber cross section. AQ55S is a commercially available water dispersible amorphous sulphonated copolyester (Eastman Chemical Company, Kingsport, TN). The 55 in the polymer name indicates a glass transition temperature of $55^{\circ} \mathrm{C}$. The water dispersible nature of AQ55S is attributed to sodiosulpho groups on the polymer backbone. AQ55S is readily disperses in water at temperature above $55^{\circ} \mathrm{C}$, making it an attractive sacrificial component compared to polymers that require solvent to disperse.

While many studies have reported on the successful implementation and utilization of PLA and other polymers for tissue engineering scaffolds, critical challenges remain with large scale fabrication and scale up of biomimetic scaffolds. We hypothesize that nonwoven scaffolds composed of PLA are well suited to meet this need. In general, nonwovens are an arrangement of random fibers bonded together to create a web or fabric. The fibrillar structure of nonwovens mimics that of native extracellular matrix (ECM), and provides an ideal environment for cellular attachment and proliferation [38-40]. In particular, we propose that, carded nonwoven fabrication techniques are capable of producing repeatable, scalable, high speed, and economical scaffolds from a 
wide variety of fiber types, including PLA. In the carding process, staple fibers (short fibers of about $5 \mathrm{~cm}$ in length) are first separated into individual filaments and subsequently entangled together (Figure 1c). Fiber entanglement is achieved via a series of specialized combed rollers, and the resultant web can be layered many times to achieve a desired thickness (termed crosslapping). Finally, the structure is locked in place by bonding the fibers via a variety of methods, such as needle punching, hydroentangling, thermal bonding, or chemical adhesives [41-44].

The goal of this study was to use carding technology to fabricate nonwoven scaffolds for bone tissue engineering applications and to test these scaffolds for their ability to support hASC viability, proliferation, and osteogenic differentiation while exposed to fluid shear stresses at magnitudes consistent with those that occur in vivo. The high surface area and gilled structure of the fibers described here makes them an attractive candidate for nonwoven tissue engineering scaffolds seeded with stem cells and mechanically stimulated with PFF. We hypothesized that the gilled structure would lead to enhanced mass transport properties via capillary action, resulting in locally increased levels of shear stress magnitudes, and increased osteogenic differentiation of hASC seeded on the scaffolds. 


\section{Materials and Methods}

\subsection{Fabrication of Gilled Fiber Scaffolds}

\subsubsection{Fabrication of Gilled Multifilaments}

PLA grade 6100D (NatureWorks LLC, Minnetonka, MN) and AQ55S

(Eastman Chemical Company, Kingsport, TN) were used for creation of all fibers.

Prior to filament spinning, the rheological properties of pure PLA and AQ55S were determined on a Rosand $\mathrm{RH} 7$ capillary rheometer (Malvern Instruments, Malvern, UK). Polymers were dried overnight under vacuum at 85 and $40{ }^{\circ} \mathrm{C}$ for PLA and AQ55S, respectively, to remove any absorbed water. Approximately 35 $\mathrm{g}$ were loaded into the rheometer chamber fitted with a long die $(16 \mathrm{~mm}$ length and $1 \mathrm{~mm}$ diameter) and subjected to a shear rate sweep from 20-10,000 1/s at constant temperature. PLA and AQ55S were each evaluated at 230 and $250^{\circ} \mathrm{C}$.

Gilled fiber multifilaments were fabricated using a winged fiber spinnerette (NatureWorks LLC, Minnetonka, MN). Fabrication of winged fibers, consisting of a solid fiber with multiple "winged" projections with a cross section approximating an asterisk has been previously described [45]. This is the first study to report the fabrication of gilled fibers using a winged fiber spinnerette (the hollow gilled channel is shaped like a winged fiber). In brief, PLA was loaded as the core polymer with AQ55S forming the bicomponent sheath at a $50: 50$ ratio by weight $(w / w)$. Multifilaments were extruded at a throughput of 0.9 grams per hole per minute (ghm) and collected on bobbins (cylinders on which filaments were wound) at a winding speed of $2100 \mathrm{~m} / \mathrm{min}$ heated to $125^{\circ} \mathrm{C}$. Goulston PL-859 spin finish (Goulston Technologies INC, Monroe, NC) was applied to the spinline 
prior to winding to prevent fibers from adhering to each other and the guide rolls.

Round fiber cross section multifilaments composed of pure PLA were extruded and collected on bobbins under similar processing conditions for the fabrication of control fibers of the same fiber diameter as experimental gilled multifilaments (Figure 1a).

\subsubsection{Fabrication of Carded Scaffolds}

Gilled fiber and round PLA control multifilaments were unwound, crimped (heat set into a zig-zag pattern), and cut into $5 \mathrm{~cm}$ staple fibers for the fabrication of carded scaffolds (Figure 1b) at the Nonwovens Institute (NWI) pilot facilities (NWI, North Carolina State University, Raleigh, NC). Staple fibers were carded

on a model carding unit at NWI at a basis weight of $200 \mathrm{~g} / \mathrm{m}^{2}$ (gsm) (Figure 1c). Scaffold structure was locked into place via needle punching on an Asselin A.50RL 4 board needle loom. Fabrics were bonded at a needle punch density (npd) of 50 strokes $/ \mathrm{cm}^{2}$ on the top and bottom surfaces for a total npd of 100 strokes $/ \mathrm{cm}^{2}$ (Figure 1d).

The gilled fiber cross section was exposed by washing the gilled fabrics in agitated deionized (DI) water at $85^{\circ} \mathrm{C}$ for 15 minutes containing $250 \mu \mathrm{L}$ surfactant per $1 \mathrm{~L} \mathrm{DI}$ water to reduce surface tension and aid in removal of AQ55S (Figure 1e). Gilled scaffolds were dried in an oven at $40^{\circ} \mathrm{C}$ overnight to remove any absorbed water prior to weighing before the washing procedure. Washed scaffolds were rinsed several times in fresh DI water and allowed to dry overnight at $40^{\circ} \mathrm{C}$ prior to being weighed to determine weight loss. 


\subsubsection{Scaffold Characterization}

PLA control, gilled unwashed, and gilled scaffold surfaces and fiber cross sections were imaged on a Phenom G2 Pro scanning electron microscope (SEM) (PhenomWorld, Eindhoven, Netherlands). Fiber cross sections were prepared by drying the scaffolds overnight at $40{ }^{\circ} \mathrm{C}$ followed by fracturing under liquid nitrogen using a razor. Scaffold SEM surface images were used to determine average fiber diameter using ImageJ software $(\mathrm{NIH}$, Bethesda, $\mathrm{MD})$ with an average of at least 25 fibers measured for each scaffold type. The fiber density of gilled fibers was determined empirically from direct observation of fiber cross sections using SEM imaging after washing. Representative fiber cross sections were converted to threshold images using ImageJ software. The total fiber cross sectional area as well as the hollow internal area was then calculated using Image to determine the percentage of hollow area in each fiber cross section. Fiber density was then calculated based on total area, less the hollow area, assuming a density of pure PLA $\left(1.24 \mathrm{~g} / \mathrm{cm}^{3}\right)$.

Scaffold thickness was measured on a Hanatek FT3 precision thickness gauge (East Sussex, UK) ( $n=10$ per scaffold) taken at random points along the scaffold width and length at least $5 \mathrm{~cm}$ away from the scaffold edge. Mean flow pore size of scaffolds was determined using a Porous Materials INC advanced capillary flow porometer (Ithaca, NY). GalWick was used as the wetting agent using the wet up/dry up no wait at dry method per manufacturer's instructions. Peak load was determined for each scaffold type via a tensile strip test to failure on an Instron 4400R (Norwood, MA). Specific surface area of PLA control, gilled 
unwashed, and gilled scaffolds was determined using the Brunauer-EmmettTeller (BET) method [46] on a Quantachrome ASiQwin automated gas sorption chamber (Quantachrome Instruments, Boynton Beach, FL). An outgassing temperature of $40^{\circ} \mathrm{C}$ was employed to ensure temperature did not exceed the glass transition temperature of $\mathrm{AQ} 55 \mathrm{~S}\left(55^{\circ} \mathrm{C}\right)$ with Krypton as the analysis gas.

\subsection{Scaffold Cell Culture and Application of PFF}

\subsubsection{Scaffold seeding}

Scaffolds were cut into 5/8 inch diameter circular scaffolds and were sterilized for four hours in $70 \%$ ethanol followed by rinsing five times in phosphate buffered saline (PBS) in 12 well non-tissue culture treated polystyrene plates. Scaffolds were then soaked in complete growth medium (CGM: Eagle $\alpha$ Minimum Essential Medium, 10\% fetal bovine serum, 2 mM L-glutamine, 100 units $/ \mathrm{mL}$ penicillin, and $100 \mu \mathrm{g} / \mathrm{mL}$ streptomycin) for 12 hours prior to cell seeding. Scaffolds were then seeded with a second passage human adipose derived stem cell pooled pre-menopausal, age and gender matched superlot isolated from five female donors that we have previously described [29]. Human ASC were obtained following an IRB exempt protocol (UNC 10-0201) from excess liposuction waste tissue from procedures performed at the University of North Carolina at Chapel Hill. Human ASC were cultured in $75 \mathrm{~cm}^{2}$ tissue culture treated flasks to $75 \%$ confluency, trypsinized, and resuspended in CGM at 200,000 cells $/ \mathrm{mL}$. Scaffolds were seeded at 20,000 cells $/ \mathrm{cm}^{2}$ and hASC were allowed to attach for one hour in a humidified incubator at $37^{\circ} \mathrm{C}$ and $5 \% \mathrm{CO}_{2}$. 
After the one hour attachment period, wells were flooded with CGM and cultured in the incubator overnight. CGM was then aspirated and scaffolds were carefully turned and seeded with an additional $20,000 \mathrm{cells} / \mathrm{cm}^{2}$ and allowed to attach and incubated overnight. Scaffolds were then transferred to new tissue culture plates and allowed to proliferate in CGM for an additional seven days, with media changes every two days.

Cellular proliferation was tracked over the seven day expansion period on days $1,3,5$, and 7 using the AlamarBlue ${ }^{\mathrm{TM}}$ assay (BioRad AbD Serotec, Oxford, UK). CGM was aspirated and scaffolds were carefully washed twice with phosphate buffered saline (PBS) and subsequently flooded with CGM containing AlamarBlue $^{\mathrm{TM}}$ at a concentration of $10 \%$ by volume $(\mathrm{v} / \mathrm{v})$ and transferred to a humidified incubator at $37{ }^{\circ} \mathrm{C}$ and $5 \% \mathrm{CO}_{2}$ for three hours. $200 \mu \mathrm{L}$ of AlamarBlue $^{\mathrm{TM}}$ containing medium was the removed and transferred to a 96 well plate and absorbance read in triplicate on a GENios microplate reader (Tecan,

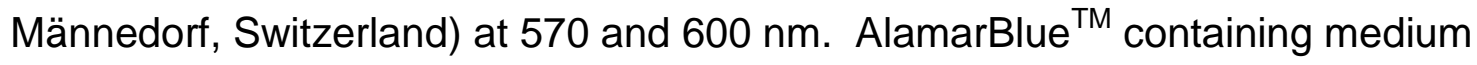
was then aspirated, scaffolds were washed three times in PBS, and flooded with fresh CGM.

Cellular viability was analyzed on days $1,3,5$, and 7 using a mammalian Live/Dead viability kit (Invitrogen, Molecular Probes, Eugene, OR). Live/Dead scaffolds were rinsed twice in PBS and incubated protected from light at $37^{\circ} \mathrm{C}$ in PBS containing $3 \mu \mathrm{M}$ calcein AM (live cells, stained green) and $4 \mu \mathrm{M}$ ethidium homodimer-1 (dead cells, stained red) for 15 minutes. Scaffolds were then 
mounted on glass slides and imaged on a Leica DM5500B fluorescence microscope (Leica Microsystems, Wetzlar, Germany) at 10x magnification.

\subsubsection{Application of PFF}

The PFF shear reactor application system consisted of eight individual fluid shear chambers (Tissue Growth Technologies, Minnetonka, MN) connected to a fluid distribution manifold (Figure 2b). CGM was supplied from a reservoir (Figure 2a) through the manifold to the shear chambers (Figure 2d) via a MasterFlex L/S 7519-25 peristaltic pump (Cole-Parmer, Vernon Hills, IL) through gas permeable tubing (Figure 2c) (PharMed, Cole-Parmer) at a specified volumetric flow rate (Equations 1 and 2). All shear chamber and pump components were sterilized in an autoclave and assembled under aseptic conditions in a biological safety cabinet. After the seven day expansion period, hASC-seeded scaffolds were loaded into the shear chambers and connected to the bioreactor pump apparatus. The tubing lines were primed with CGM prior to being connected to the scaffold loaded shear chambers and the entire closed system was then transferred to a humidified incubator at $37{ }^{\circ} \mathrm{C}$ and $5 \% \mathrm{CO}_{2}$. Volumetric flow rates resulting in desired physiological shear stress magnitudes

[19] of 3, 6, and 9 dyne $/ \mathrm{cm}^{2}$ were calculated according to Equations 1 and 2 and scaffolds were subjected to one hour of PFF at each shear stress. These shear stress magnitudes were chosen in line with previous studies that have shown relatively low shear stress magnitudes are capable of generating a mechanosensitive response $[47,48]$. Unstimulated/static controls were kept in 
the same system in the incubator but without application of PFF (referred to as 0

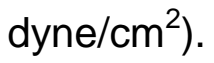

$$
\begin{aligned}
& v=\frac{\tau R}{2 \mu} \\
& Q=A v
\end{aligned}
$$

\section{Equation 1}

Equation 2

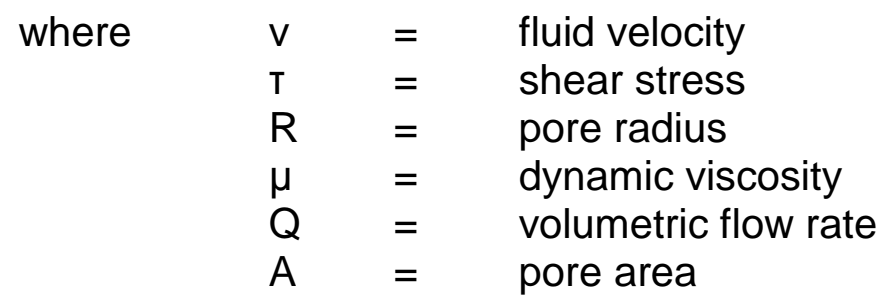

Cellular viability of hASC on scaffolds subjected to PFF at each shear stress magnitude were analyzed immediately after application of one hour PFF in the same manner as Live/Dead scaffolds analyzed during the expansion period. Three scaffolds per scaffold type and shear stress magnitude were collected in $1.5 \mathrm{~mL}$ RNase free tubes containing $350 \mu \mathrm{L}$ lysis buffer RLT (Qiagen, Valencia, $\mathrm{CA}$ ) and repeatedly ground with an RNase free pestle and frozen at $-80^{\circ} \mathrm{C}$.

Human ASC seeded scaffolds exposed to PFF were thawed on ice and cell lysates were processed in QiaShredder homogenizers (Qiagen). Total RNA was isolated using an RNeasy mini kit according to the manufacturer's instructions (Qiagen). Isolated RNA was quantified on a NanoDrop 2000 UV-Vis Spectrophotometer (Thermo Fisher Scientific, Waltham, MA). Following RNA isolation, $48 \mathrm{ng}$ of RNA for each sample was used for the generation of cDNA using an OriGene first strand cDNA synthesis kit according to the manufacturer's 
instructions (OriGene, Rockville, MD) on an Eppendorf Mastercycler Nexus Gradient Thermal Cycler (Eppendorf, Hamburg, Germany) and quantified using a NanoDrop 2000. Real time reverse transcriptase polymerase chain reaction (RTqPCR) was performed using a TaqMan gene expression master mix (Applied Biosystems Fisher Life Technologies, Waltham, MA) with $2 \mu \mathrm{L}$ of cDNA per sample $(n=3)$ on an ABI Prism 7000 real time thermocycler (Applied Biosystems Fisher Life Technologies, Waltham, MA). Gene expression of runt related transcription factor 2 (RUNX2) was measured and normalized to hypoxanthine phosphoribosyltransferase 1 (HPRT 1). Both primers were purchased from Applied Biosystems (Fisher Life Technologies, Waltham, MA). Fold change in expression was calculated using the comparative threshold $\left(\mathrm{C}_{\mathrm{T}}\right)$ method as described by Schmittgen and Livak [49].

\subsubsection{Statistical Analysis}

An unpaired student's t-test was used to analyze statistical difference for scaffold characterization and proliferation assays. A one-way ANOVA was used for statistical analysis of PCR data. Error bars represent standard error of the mean. Statistical significance is indicated as $p<0.05$. 


\section{Results}

\subsection{Fabrication of Gilled Fiber Scaffolds}

\subsubsection{Fabrication of Gilled Multifilaments}

The rheological properties of PLA and AQ55S were determined prior to fabrication of multifilaments. Capillary rheometry results indicated that AQ55S exhibits a relative viscosity $2-6$ times greater than that of pure PLA, depending on shear rate and temperature (Figure 3). As expected, viscosity decreased with increasing shear rate; with shear profiles exhibiting shear thinning behavior typical of polymer melts. Multifilaments were successfully fabricated using a winged fiber spinnerette with PLA loaded as the core polymer and AQ55S as the sheath polymer. Multifilaments were successfully fabricated and collected on bobbins for subsequent production of staple fibers and carded fabrics. Control pure PLA round cross section fibers were also collected under similar spinning conditions, resulting in PLA fibers of the same diameter compared to experimental gilled fibers (Figure 4).

\subsubsection{Fabrication of Carded Scaffolds}

Multifilaments were processed into staple fibers for subsequent carded fabric production (Figure 1b). Filaments were unwound and crimped into $5 \mathrm{~cm}$ staple fibers. No fiber breakage during crimping and cutting was observed for pure PLA controls or for experimental gilled fibers. Staple fibers were successfully converted to carded fabrics on a small model carding unit (Figure 1c). A uniform basis weight of $200 \mathrm{gsm}$ was achieved for both scaffold types. 
Scaffolds were bonded via needling on both sides at a total needle punch density of 100 strokes $/ \mathrm{cm}^{2}$ (Figure 1d).

\subsubsection{Removal of the Sacrificial Component}

Gilled scaffolds were washed in gently agitated DI water at $85^{\circ} \mathrm{C}$ for 15 minutes. Mechanical bonding via needling was sufficient to withstand the washing procedure, with little fiber loss observed during the washing procedure. Washed scaffolds retained their nonwoven morphology with no significant changes in physical dimensions observed (Figure 4). Visual dissolution of the AQ55S component was observed within one minute of submersion in DI water as an opaque milky substance leaving the scaffold surface. The washing procedure resulted in fabric weight loss of $52.7 \pm 0.4 \%$, indicating an average washing efficiency of $107.61 \pm 0.04 \%$.

Scaffold surfaces and fiber cross section SEM images were captured to determine scaffold and fiber morphology (Figure 4). Fiber diameter of PLA control, gilled unwashed, and gilled fibers was well conserved and resulted in fiber diameters of $23.8 \pm 2.5,24.4 \pm 2.6$, and $23.5 \pm 1.2 \mu \mathrm{m}$, respectively. All fiber types resulted in a round outer diameter morphology (Figure $\mathbf{4}, \mathbf{b}_{1}-\mathbf{b}_{3}$ and $\left.\mathbf{c}_{1}-\mathbf{c}_{3}\right)$. Additionally, a portion of the gilled fibers exhibited cracks on the fiber surface, exposing the internal fiber structure (Figure $\mathbf{4}, \mathbf{a}_{3}-\mathbf{C}_{3}$ ). Unwashed gilled fiber cross sections revealed successful fabrication of a winged fiber cross section, with distinct polymer interfaces observed between PLA and AQ55S (Figure $\mathbf{4}, \mathbf{b}_{\mathbf{2}}$ and $\mathbf{c}_{2}$ ). The washing procedure resulted in removal of the AQ55S 
component, leaving behind an inverted winged fiber cross section, consisting of an outer PLA skin and PLA finger like structures extending toward a hollow core (Figure 4, $b_{3}$ and $c_{3}$ ). The resultant structure resembled the gills on the underside of a mushroom cap; hence the name gilled fibers.

Gilled fiber density was calculated from representative SEM cross section images using ImageJ software (Figure 5). The cross sectional hollow area occupied a volume of $175 \mu \mathrm{m}^{2}$ with total area of the fiber occupying $446 \mu \mathrm{m}^{2}$. From these measurements, the fiber density of gilled fibers was calculated as $0.67 \mathrm{~g} / \mathrm{cm}^{3}$, compared to a pure PLA fiber density of $1.24 \mathrm{~g} / \mathrm{cm}^{3}$, representing a $46 \%$ decrease in fiber density. BET surface area measurements indicated PLA control, gilled unwashed, and gilled fiber surface areas of $0.066,0.104$, and $1.677 \mathrm{~m}^{2} / \mathrm{g}$, respectively (Figure 6).

\subsubsection{Scaffold Characterization}

Fiber and scaffold properties are provided in Table 1. Thickness of PLA control, gilled unwashed and gilled scaffolds agreed well and resulted in scaffold thicknesses of $2750 \pm 72,2894 \pm 109$, and $2600 \pm 129 \mu \mathrm{m}$, respectively. Pore sizes of 73 and $84 \mu \mathrm{m}$ were measured for PLA control and gilled unwashed scaffolds. The washing procedure resulted in slightly increased pore size of 92 $\mu \mathrm{m}$ for the gilled scaffolds. Mechanical properties of acellular scaffolds were analyzed via tensile testing to failure prior to cell seeding. Representative engineering stress strain curves are provided in Figure 7a. Tensile test data 
resulted in peak loads for PLA control, gilled unwashed, and gilled scaffolds of $31.7 \pm 1.7,27.3 \pm 6.3$, and $55.0 \pm 10.1 \mathrm{~N}$, respectively (Figure $7 \mathrm{~b}$ ).

Table 1. Fiber and scaffold properties of PLA control, gilled unwashed, and gilled scaffolds.

\begin{tabular}{|c|c|c|c|}
\hline & $\begin{array}{l}\text { PLA } \\
\text { Control }\end{array}$ & $\begin{array}{l}\text { Gilled } \\
\text { Unwashed }\end{array}$ & Gilled \\
\hline $\begin{array}{l}\text { Fiber Diameter } \\
{[\mu \mathrm{m}]}\end{array}$ & $23.8 \pm 2.5$ & $24.4 \pm 2.6$ & $23.5 \pm 1.2$ \\
\hline 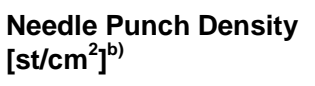 & 100 & 100 & 100 \\
\hline $\begin{array}{l}\text { Basis Weight } \\
{[\mathrm{gsm}]^{\mathrm{c})}}\end{array}$ & 200 & 200 & 200 \\
\hline $\begin{array}{l}\text { Thickness } \\
{[\mu \mathrm{m}]}\end{array}$ & $2750 \pm 72$ & $2894 \pm 109$ & $2600 \pm 129$ \\
\hline $\begin{array}{l}\text { Pore Size } \\
{[\mu \mathrm{m}]}\end{array}$ & 73 & 84 & 92 \\
\hline $\begin{array}{l}\text { Surface Area } \\
{\left[\mathrm{m}^{2} / \mathrm{g}\right]}\end{array}$ & 0.066 & 0.104 & 1.677 \\
\hline $\begin{array}{l}\text { Peak Load } \\
\text { [N] }\end{array}$ & $31.7 \pm 1.7$ & $27.3 \pm 6.3$ & $55.0 \pm 10.1$ \\
\hline $\begin{array}{l}\text { Strain at Break } \\
{[\%]}\end{array}$ & $136.5 \pm 7.4$ & $113.6 \pm 3.8$ & $78.7 \pm 2.5$ \\
\hline
\end{tabular}

\subsection{Human ASC-Seeded Gilled Scaffolds Subjected to PFF}

\subsubsection{Proliferation and Viability of hASC}

Human ASC proliferated over the seven day expansion period on PLA control and gilled scaffolds (Figure 8). No significant differences were observed over the first five days; however on day seven gilled scaffolds exhibited a significant increase in proliferation compared to PLA control scaffolds. Little change was observed in the number of viable cells (stained green) for both 
scaffold types over the first five days (Figure $9 a_{1}, \mathbf{a}_{1}-\mathbf{a}_{3}$ and $\mathbf{a}_{5}-\mathbf{a}_{7}$ ); however an increase in the number of viable cells was observed on day seven (Figure $\mathbf{9 a}, \mathbf{a}_{\mathbf{4}}$ and $a_{8}$ ). Further, a greater number of dead cells (stained red) were observed for all time points on PLA control scaffolds compared to gilled scaffolds.

\subsubsection{Application of PFF}

A representative image of the PFF apparatus is provided in Figure 2. Bioreactor assembly was carried out under aseptic conditions in a biological safety cabinet. Prior to subjecting scaffolds to PFF, volumetric flow rate was validated with CGM. All chambers operated successfully and delivered equal volumes of CGM according to the specified flow rate (Equations 1 and 2). No leakage was observed during application of PFF. RT-qPCR was performed after the application of PFF to determine the effects on hASC mRNA expression of RUNX2. There were no significant differences between unstimulated scaffolds, however hASC seeded on gilled scaffolds exhibited significantly increased RUNX2 expression for shear stress magnitudes of 3 and $6 \mathrm{dyne} / \mathrm{cm}^{2}$ (Figure 10). Both scaffold types led to a significant increase in RUNX2 expression for 9 dyne $/ \mathrm{cm}^{2}$ compared to unstimulated controls, however there was no statistical difference between the scaffold types at 9 dyne $/ \mathrm{cm}^{2}$.

Live/Dead cellular viability images were captured immediately after application of PFF to determine the effects of applied shear stress on hASC viability (Figure 9b). Some reduction in the number of viable cells was observed on PLA control scaffolds for all shear stress magnitudes compared to 
unstimulated controls (Figure $\mathbf{9 b}, \mathbf{b}_{2}-\mathbf{b}_{4}$ ). Some decrease in the number of viable cells also appeared to occur on gilled scaffolds, although to a lesser extent than PLA controls (Figure 9b, $\mathbf{b}_{6}-\mathbf{b}_{\mathbf{8}}$ ). Little difference was observed between shear stress magnitudes applied with regard to the number of viable cells observed for gilled scaffolds. A greater number of dead cells were observed on PLA control scaffolds compared to gilled scaffolds for all shear stress magnitudes.

\section{Discussion}

\subsection{Fabrication of Gilled Fiber Scaffolds}

We have described a method for successful bicomponent multifilament spinning of PLA and AQ55S using a winged fiber spinnerette, with PLA loaded as the core and AQ55S as the sheath. With this arrangement, an inverted winged fiber cross section (termed gilled fiber) was created, with the PLA component moving from the core and replacing AQ55S as the sheath component and vice versa. The gilled cross section was clearly defined and both polymers and the polymer interface could be observed under SEM imaging (Figure $\mathbf{4}, \mathbf{b}_{\mathbf{2}}-\mathbf{b}_{\mathbf{3}}$ and $\left.\mathbf{c}_{2}-\mathbf{c}_{3}\right)$. We believe that phase inversion of the polymer components was likely due to viscosity differences between PLA and AQ55S. AQ55S was measured to be 2-6 times more viscous than PLA. It has been demonstrated previously that in the case of two component polymer melt systems, phase inversion is likely to occur when there is a large difference in viscosity [50-53]. Ratnagiri and Scott have demonstrated that phase inversion is favored in systems containing a low 
viscosity and low melting point minor component [50]. Li et al. have shown that the viscosity ratio, weight percentage, and interfacial tension between components as well as the processing conditions will affect the resultant blend morphology [52]. Blends composed of polymers with similar viscosities (viscosity ratio at or near one) tend to form co-continuous structures for weight ratios between $30-70 \%$ [53]. In the present work, it is likely that the large difference in viscosity of the two components is responsible for phase inversion and formation of the gilled fiber cross section. Future work, including loading AQ55S as the core component and PLA as the sheath during filament spinning, could shed further details on the observed phenomenon. Further, studies are needed to determine changes in the formation of the gilled fiber cross section through variation of polymer melt temperature (to vary the viscosity ratio) to validate this hypothesis. Lastly, additional polymer systems, including alternative sacrificial and fiber forming polymer components are needed to determine if the gilled fiber cross section is unique to the PLA-AQ55S system described here.

Gilled fiber multifilaments were successfully fabricated into staple fibers and subsequently carded to form nonwoven scaffolds. Staple fiber processing, carding, and bonding via needle punching did not affect the gilled fiber cross section. Needle punching provided sufficient mechanical stability to withstand the washing procedure. A dramatic increase of over $1500 \%$ in specific surface area was observed for gilled fibers compared to unwashed controls, however additional replicates of surface area analysis are needed to validate these findings. Further, a washing efficiency greater than $100 \%$ was observed for 
gilled fiber scaffolds, indicating complete removal of the AQ55S component was likely achieved. The additional weight loss was likely due to individual fibers lost during the washing procedure, and removal of water-soluble spin finish applied during filament spinning. Spin finish is a lubricating liquid (of varied composition, depending on the type of polymer being spun) applied during spinning to prevent filaments from adhering to the collection rolls and to one another. Tensile testing resulted in an increase in peak load for gilled fiber scaffolds compared to unwashed and PLA controls, however this increase was not significant. There was a significant decrease in strain at break for unwashed and gilled fiber scaffolds compared to control scaffolds, as well as a significant decrease between unwashed gilled and gilled fiber scaffolds. Differences in PLA control and unwashed gilled fiber scaffold strain at break was attributed to winding speed and the inclusion of the AQ55S component in the gilled fibers. Winding speed was kept constant for each fiber type to fabricate fibers of similar diameter. However, pure PLA may be collected at higher winding speeds, resulting in polymer chain orientation in the fiber direction, leading to increased tensile strength and decreased strain at break. Pure PLA fibers were likely partially oriented, leading to higher strain at break compared to gilled fiber scaffolds. Inclusion of the AQ55S component resulted in lower maximum winding speeds, and strain at break is a result of contributions from both polymer components. Gilled fiber scaffolds led to an additional decrease in strain at break compared to PLA and unwashed gilled controls. The washing procedure was carried out 
above the glass transition temperature of PLA, resulting in relaxation of the polymer chain orientation imparted during fiber spinning.

Although in this study we have focused on gilled scaffolds for tissue engineering applications, gilled fibers are attractive candidates for a variety of applications requiring high surface area, such as biomedical separation processes. We have shown that needle punching is sufficient for providing mechanical integrity, however, other bonding methods such as hydroentangling, chemical, and thermal could also be employed. In addition, while we have shown successful fabrication of carded scaffolds, our results suggest production of gilled fibers could be extended to other woven and nonwoven applications such as knits, woven fabrics, and direct fabrication of continuous filament nonwovens such as bicomponent spunbond fabrics, providing an array of fabrication platforms that could be tailored for specific applications. Beyond the specificity of the winged fiber spinnerette, post production of gilled fibers into a wide range of fiber based materials may be realized.

\subsection{Carded Gilled Fiber Tissue Engineering Scaffolds}

The novel gilled fiber scaffolds described here exhibited promise as tissue engineering scaffolds using hASC. Cellular proliferation was significantly increased on gilled scaffolds compared to solid fiber controls after seven days in static culture (Figure 8). Further, fewer dead cells were observed on gilled scaffolds over the culture period (Figure 9a). SEM surface images of scaffolds exhibited the presence of linear cracks along the surface of a portion of fibers, 
originating between fingerlike PLA internal wing projections (Figure $\mathbf{4}, \mathbf{a}_{\mathbf{3}}$ ). We speculate this effect was due to fracturing during the needle punching process. For the purposes of this study, these fracture lines may have served a beneficial purpose by exposing the internal hollow gilled channel, facilitating fluid flow. The hollow gilled channels may provide enhanced mass transport through capillary action, promoting better distribution of nutrients and oxygen throughout the thickness of the scaffolds, as well as providing a route for elimination of cellular waste products. Additional experiments including finite element modeling are needed to determine the effects of the gilled fiber morphology on fluid flow around and through the fibers and their effect on local shear stress fields. An understanding of fluid dynamics through gilled fiber scaffolds is needed to determine the ranges of shear stresses imparted to cells adhered to the scaffold.

Fibrous tissue engineering scaffolds have been used extensively for a wide range of tissue types and cell sources. Random or oriented nonwoven scaffolds are inherently biomimetic, with similar architecture to native ECM structures such as collagen fibers. Many groups have focused on electrospinning for the fabrication of nonwoven tissue engineering scaffolds because the fiber size is similar to that of ECM structures [38,54-58]. The gilled fibers reported here are on the order of $25 \mu \mathrm{m}$, much larger than native ECM structures and fibers obtained with electrospinning methods. However, we have shown here that hASC are capable of attachment, proliferation, and differentiation under pulsatile fluid flow on gilled fiber scaffolds. Kuo et al. reported that larger fibers $(1.47 \mu \mathrm{m}$, compared to 0.67 and $0.31 \mu \mathrm{m})$ increased 
proliferation of hMSCs on electrospun polyurethane scaffolds [59]. They attribute enhanced proliferation on larger fibers to enhanced migration of cells into pores within the nonwoven scaffold [59]. Interactions between stem cells and fibrous tissue engineering scaffolds is extremely complex and a number of factors can influence the attachment, migration, proliferation, differentiation, and deposition of extracellular matrix; including but certainly not limited to fiber diameter.

Human ASC seeded on gilled scaffolds exhibited an increase in RUNX2 mRNA expression, an early marker for osteogenesis $[21,60]$, for shear stress magnitudes of 3 and 6 dyne $/ \mathrm{cm}^{2}$ compared to PLA control scaffolds after one hour of PFF (Figure 10), even in the absence of chemical osteogenesis induction factors, such as $\beta$-glycerol phosphate, ascorbic acid, and dexamethasone. There was no statistical difference in RUNX2 expression between gilled and control scaffolds at 9 dyne $/ \mathrm{cm}^{2}$, although both scaffolds exhibited a significant increase compared to unstimulated controls at this shear stress magnitude. We speculate that the gilled scaffolds may have exposed hASC to local increases in shear stress magnitude compared to control scaffolds. Fluid flow through the gilled channels is expected to be increased compared to fluid flow through the macro pores in the scaffold, resulting in increased shear at the fiber surfaces. This hypothesis could explain the increase in RUNX2 mRNA expression for low magnitudes of applied shear stress. At higher fluid velocities and shear stresses, hASC may be exposed to sufficient shear stress on both gilled and control scaffolds, resulting in similar levels of RUNX2 expression. Future empirical and 
computational analyses to more precisely quantify local shear stresses observed during PFF are needed to validate this hypothesis.

Finally, a greater number of viable cells were observed on gilled scaffolds at all shear stress magnitudes analyzed (Figure 9b), suggesting gilled scaffolds promote better adhesion of hASC compared to control scaffolds. Fracture lines observed on the fiber surfaces may have exposed the internal gill structures to attached hASC, providing an ideal microenvironment for cellular attachment.

\section{Further studies are needed to verify the effect of fiber morphology on the}

\section{attachment and proliferation of hASC.}

This is the first study to describe the manufacture of novel gilled fibers and gilled fiber tissue engineering scaffolds. This study serves as a proof of concept experiment for the validation of hASC-seeded gilled fiber scaffolds as tissue engineering constructs using PFF as mechanical stimulation via shear stress. Future studies should be undertaken to further elucidate the effects of scaffold and fiber properties on the behavior of hASC, including longer PFF stimulation times over extended culture periods, other loading modalities, inclusion of chemical induction factors, analysis of early, transitional, and late osteogenic gene targets, analysis of end product expression such as cell mediated calcium accretion, and analysis of hASC spreading and infiltration throughout the scaffolds. 


\section{Conclusions}

We report here for the first time the successful fabrication of novel high surface area gilled fibers. Gilled fiber carded scaffolds were successfully fabricated from multifilament fibers with sufficient strength to withstand washing procedures and application of PFF. A hollow internal cross section with finger like PLA projections resembling those of mushrooms was realized via bicomponent filament extrusion of PLA and AQ55S. The effects of fiber morphology on the proliferation and viability of hASC, as well as the effects of varied magnitudes of applied shear stress via pulsatile fluid flow for one hour were evaluated. Gilled fibers led to a significant increase in proliferation of hASC after one week in static culture, and a greater number of viable cells compared to round fiber PLA control scaffolds. Further, in the absence of any osteogenic induction factors in the culture medium, gilled fibers led to significantly increased mRNA expression of RUNX2, an early marker for osteogenesis, for applied shear stress magnitudes of 3 and 6 dyne $/ \mathrm{cm}^{2}$. This is the first study to describe gilled fiber fabrication and their potential for tissue engineering applications. The repeatable, industrial scalable, and versatile fabrication process makes them promising candidates for a variety of scaffold-based tissue engineering applications across a variety of platforms. 


\section{Acknowledgments}

The authors would like to acknowledge the following funding sources: NWI 11-136 (EGL), NSF/CBET 1133427 (EGL), NIH CTSA 550KR71418 (EGL), and NIH CTSA 550KR61325 (EGL). 


\section{References}

[1] J.C. Bodle, A.D. Hanson, E.G. Loboa, Adipose-derived stem cells in functional bone tissue engineering: Lessons from bone mechanobiology, Tissue Eng. Part B, 17(3) (2011).

[2] P.S. Mathieu, E.G. Loboa, Cytoskeletal and focal adhesion influences on mesenchymal stem cell shape, mechanical properties, and differentiation down osteogenic, adipogenic, and chondrogenic pathways, Tissue Eng. Part B 18(6) (2012) 436-444.

[3] S.D. McCullen, C.M. Haslauer, E.G. Loboa, Musculoskeletal mechanobiology: Interpretation by external force and engineered substratum, J. Biomech. 43(1) (2010) 119-127.

[4] J.D. Kubicek, S. Brelsford, P. Ahluwalia, P.R. LeDuc, Integrated lithographic membranes and surface adhesion chemistry for threedimensional cellular stimulation, Langmuir 20 (2004) 11552-11556.

[5] T.W. Pfeiler, R.D. Sumanasinghe, E.G. Loboa, Finite element modeling of 3D human mesenchymal stem cell-seeded collagen matrices exposed to tensile strain, J. Biomech. 41(10) (2008) 2289-2296.

[6] R.D. Sumanasinghe, T.W. Pfeiler, N.A. Monteiro-Riviere, E.G. Loboa, Expression of proinflammatory cytokines by human mesenchymal stem cells in response to cyclic tensile strain, J. Cell. Physiol. 219(1) (2009) 7783.

[7] R.D. Sumanasinghe, J.A. Osborne, E.G. Loboa, Mesenchymal stem cellseeded collagen matrices for bone repair: effects of cyclic tensile strain, cell density, and media conditions on matrix contraction in vitro, J. Biomed. Mater. Res. Part A 88(3) (2009) 778-786.

[8] E.G. Loboa, T.D. Fang, S.M. Warren, D.P. Lindsey, K.D. Fong, M.T. Longaker, D.R. Carter, Mechanobiology of mandibular distraction osteogenesis: Experimental analyses with a rat model, Bone 34(2) (2004) 336-343.

[9] A.D. Hanson, S.W. Marvel, S.H. Bernacki, A.J. Banes, J. van Aalst, E.G. Loboa, Osteogenic effects of rest inserted and continuous cyclic tensile strain on hASC lines with disparate osteodifferentiation capabilities, Ann. Biomed. Eng. 37(5) (2009) 955-965.

[10] A. Charoenpanich, M.E. Wall, C.J. Tucker, D.M.K. Andrews, D.S. Lalush, E.G. Loboa, Microarray analysis of human adipose-derived stem cells in three-dimensional collagen culture: Osteogenesis inhibits bone 
morphogenic protein and Wnt signaling pathways, and cyclic tensile strain causes upregulation of proinflammatory cytokine regulators, Tissue Eng. Part A 17(21-22) (2011) 2615-2627.

[11] M. Knippenberg, M.N. Helder, B.Z. Doulabi, C.M. Semeins, P.I.J.M. Wuisman, J. Klein-Nulend, Adipose tissue-derived mesenchymal stem cells acquire bone cell-like responsiveness to fluid shear stress on osteogenic stimulation, Tissue Eng. 11(11-12) (2005) 1780-1789.

[12] J. Klein-Nulend, A.D. Bakker, R.G. Bacabac, A. Vatsa, S. Weinbaum, Mechanosensation and transduction in osteocytes, Bone 54(2) (2013) 182-190.

[13] E.H. Burger, J. Klein-Nulend, A. van der Plas, P.J. Nijweide, Function of osteocytes in bone-Their role in mechanotransduction, Int. Conf. Prog. Bone Miner. Res. 125(7) (1995).

[14] J. Puetzer, J. Williams, A. Gillies, S. Bernacki, E.G. Loboa, The effects of cyclic hydrostatic pressure on chondrogenesis and viability of human adipose- and bone marrow derived mesenchymal stem cells in threedimensional agarose constructs, Tissue Eng. Part A 19(1-2) (2013) 299306.

[15] A.R. Finger, C.Y. Sargent, K.O. Dulaney, S.H. Bernacki, E.G. Loboa, Differential effects on messenger ribonucleic acid expression by bone marrow-derived human mesenchymal stem cells seeded in agarose constructs due to ramped and steady applications of cyclic hydrostatic pressure, Tissue Eng 13(6) (2007) 1151-1158.

[16] M. Knippenberg, M.N. Helder, B.Z. Doulabi, C.M. Semeins, P.I.J.M. Wuisman, J. Klein-Nulend, Adipose tissue-derived mesenchymal stem cells acquire bone cell-like responsiveness to fluid shear stress on osteogenic stimulation, Tissue Eng. 11(11-12) (2005) 1780-1789.

[17] N.E. Ajubi, P.J. Nijweide, M.J. Alblas, E.H. Burger, Pulsating fluid flow increases prostaglandin production by cultured chicken osteocytes - $A$ cytoskeleton-dependent process, Biochem. Biophys. Res. Commun. 225(1) (1996) 62-68.

[18] S. Kapur, D.J. Baylink, K.-H.W. Lau, Fluid flow shear stress stimulates human osteoblast proliferation and differentiation through multiple interacting and competing signal transduction pathways, Bone 32(3) (2003) 241-251.

[19] M.V.J. Hukkanen, J.M. Polak, S.P.F. Hughes, Nitric Oxide in Bone and Joint Disease, Cambridge University Press, Cambridge, UK, 1998. 
[20] J. Kein-Nulend, C. Semeins, N.E. Ajubi, P.J. Nijweide, E.H. Burger, Pulsating fluid flow increases nitric oxide (NO) synthesis by osteocytes but not periosteal fibroblasts - correlation with prostaglandin upregulation, Biochem. Biophys. Commun. 217(3) (1995) 640-648.

[21] K.-S. Lee, H.-J. Kim, Q.-L. Li, X.-Z. Chi, C. Ueta, T. Komori, J.M. Wozney, E.-G. Kim, J.-Y. Choi, H.-M. Ryoo, S.-C. Bae, Runx2 is a common target of transforming growth factor $\beta 1$ and bone morphogenetic protein 2 , and cooperation between Runx2 and Smad5 induces osteoblast-specific gene expression in the pluripotent mesenchymal precursor cell line $\mathrm{C} 2 \mathrm{C} 12$, Mol. Biol. Cell. Biol. 20(23) (2000) 8783-8792.

[22] C. Correia, S. Bhumiratana, R.A. Sousa, R.L. Reis, G. Vunjak-Novakovic, Pulsatile fluid flow enhances engineered bone development by human adipose derived stem cells, Int. J. Artif. Organs 34(8) (2011).

[23] M. Mohiti-Asli, B. Pourdeyhimi, E.G. Loboa, Release profiles of tricalcium phosphate nanoparticles from poly (L-lactic acid) electrospun scaffolds with single component, core-sheath, or porous fiber morphologies: Effects on hASC viability and osteogenic differentiation, Macromol. Biosci. 12(7) (2012) 893-900.

[24] P.A. Zuk, M. Zhu, P. Ashjian, D.A. de Ugarte, J.I. Huang, H. Mizuno, Z.C. Alfonso, J.K. Fraser, P. Benhaim, M.H. Hedrick, Human adipose tissue is a source of multipotent stem cells, Molec. Biol. Cell 13 (2002) 4279-4295.

[25] P.A. Zuk, M. Zhu, H. Mizuno, J. Huang, W. Futrell, A.J. Katx, P. Benhaim, H.P. Lorenz, M.H. Hedrick, Multilineage cells from human adipose tissue: Implications for cell-based therapies, Tissue Eng. 7(2) (2001) 211-229.

[26] J. Gimble, F. Guilak, Adipose-derived adult stem cells: Isolation, characterization, and differentiation potential, Cytotherapy 5(5) (2003) 362369.

[27] F. Guilak, H. Awad, B. Fermor, H. Leddy, J. Gimble, Adipose-derived adult stem cells for cartilage tissue engineering, Biorheology 41 (2004).

[28] B.M. Strem, M. Zhu, Z. Alfonso, E.J. Daniels, R. Schreiber, R. Beygui, W.R. MacLellan, M.H. Hedrick, J.K. Fraser, Expression of cardiomyocytic markers on adipose tissue-derived cells in a murine model of acute myocardial injury, Cytotherapy 7(3) (2005) 282-291.

[29] J.C. Bodle, S.D. Teeter, B. Hluck, J.W. Hardin, S.H. Bernacki, E.G. Loboa, Age-related effects on the potency of human adipose derived stem cells: Creation and evaluation of superlots and implications for musculoskeletal tissue engineering applications, Tissue Eng. Part C 12 (2014) 972-983. 
[30] S.D. McCullen, J. Zhan, M.L. Onorato, S.H. Bernacki, E.G. Loboa, Effect of varied ionic calcium on human adipose-derived stem cell mineralization, Tissue Eng. Part A 16(6) (2010) 1971-1981.

[31] P.S. Mathieu, J.C. Bodle, E.G. Loboa, Primary cilium mechanotransduction of tensile strain in 3D culture: Finite element analyses of strain amplification caused by tensile strain applied to a primary cilium embedded in a collagen matrix, J. Biomech. 47(9) (2014) 2211-2217.

[32] C.M. Haslauer, M.R. Avery, B. Pourdeyhimi, E.G. Loboa, Translating textiles to tissue engineering: Creation and evaluation of microporous, biocompatible, degradable scaffolds using industry relevant manufacturing approaches and human adipose derived stem cells, J. Biomed. Mater. Res. Part B Appl. Biomater. 103(5) (2015) 1050-1058.

[33] S.D. McCullen, P.R. Miller, S.D. Gittard, R.E. Gorga, B. Pourdeyhimi, R.J. Narayan, E.G. Loboa, In situ collagen polymerization of layered cellseeded electrospun scaffolds for bone tissue engineering applications, Tissue Eng. Part C 16(5) (2010) 1095-1105.

[34] S.D. McCullen, Y. Zhu, S.H. Bernacki, R.J. Narayan, B. Pourdeyhimi, R.E. Gorga, E.G. Loboa, Electrospun composite poly(L-lactic acid)/tricalcium phosphate scaffolds induce proliferation and osteogenic differentiation of human adipose-derived stem cells, Biomed. Mater. 4(3) (2009).

[35] R.D. Sumanasinghe, C.M. Haslauer, B. Pourdeyhimi, E.G. Loboa, Melt spun microporous fibers using poly (lactic acid) and sulfonated copolyester blends for tissue engineering applications, J. Appl. Polym. Sci. 117 (2010) 3350-3361.

[36] M.S. Lopes, A.L. Jardini, R.M. Filho, Poly(lactic acid) production for tissue engineering applications, Procedia Eng. 42 (2012) 1402-1413.

[37] K. Rezwan, Q.Z. Chen, J.J. Blaker, A.R. Boccaccini, Biodegradable and bioactive porous polymer/inorganic composite scaffolds for bone tissue engineering, Biomater. 27(18) (2006) 3413-3431.

[38] W.-J. Li, K.G. Danielson, P.G. Alexander, R.S. Tuan, Biological response of chondrocytes cultured in three-dimensional nanofibrous poly $(\varepsilon-$ caprolactone) scaffolds, J. Biomed. Mater. Res. Part A 67(4) (2003) 11051114.

[39] J.A. van Aalst, C.R. Reed, L. Han, T. Andrady, M. Hromadka, S. Bernacki, K. Kolappa, J.B. Collins, E.G. Loboa, Cellular incorporation into electrospun nanofibers: retained viability, proliferation, and function in fibroblasts, Ann. Plast. Surgery 60(5)(2008) 577-583. 
[40] Q.P. Pham, U. Sharma, A.G. Mikos, Electrospinning of polymeric nanofibers for tissue engineering applications: a review,Tissue Eng. 12(5) (2006) 1197- 1211.

[41] C.-F.J. Kuo, Y.-C. Chou, T.-Y. Lin, Automatic control of roller carding machine. Part I: Modeling and validation of roller carding machine, Text. Res. J. 82(1) (2011) 3-10.

[42] P. Danielczyk, J. Stadnicki, Optimization of the structural form of the carding machine main cylinder, Text. Res. J. 82(18) (2012) 1897-1905.

[43] C.A. Lawrence, Fundamentals of Spun Yarn Technology, CRC Press, Boca Raton, FL, 2003.

[44] S.K. Batra, B. Pourdeyhimi, Introduction to Nonwovens Technology, DEStech Publications, Lancaster, PA, 2011.

[45] B. Pourdeyhimi, W. Chappas, H. M. Barnes, Articles containing woven or non-woven ultra-high surface area macro polymeric fibers, U.S. Patent 0 $133980,2013$.

[46] S. Brunauer, P.H. Emmett, E. Teller, Gases in multimolecular layers, J. Chem. Soc. 407(1) (1938).

[47] M.R. Kreke, L.A. Sharp, Y.W. Lee, A.S. Goldstein, Effect of intermittent shear stress on mechanotransductive signaling and osteoblastic differentiation of bone marrow stromal cells, Tissue Eng. Part A 14(4) (2008) 529-537.

[48] R.L. Steward, C.-M. Cheng, D.L. Wang, P.R. LeDuc, Probing cell structure responses through a shear and stretching mechanical stimulation technique, Cell Biochem. Biophys. 56(115-124) (2010) 115-124.

[49] T.D. Schmittgen, K.J. Livak, Analyzing real-time PCR data by the comparative CT method, Nat. Protoc. 3(6) (2008) 1101-1108.

[50] R. Ratnagiri, C. R. Scott, Phase inversion during compounding - The effect of viscosity variation with temperature, Proc. Soc. Plast. Eng. Ann. Tech. Conf. 43 (1997).

[51] R.T. Tol, G. Groeninckx, I. Vinckier, P. Moldenaers, J. Mewis, Phase morphology and stability of co-continuous (PPE/PS)/PA6 and PS/PA6 blends: Effect of rheology and reactive compatibilization, Polym. 45(8) (2004) 2587-2601. 
[52] M. Li, C.S. Wang, H.P. Wang, Fabrication of hierarchical microporous structures with controlled morphology and topography, Adv. Mater. Res. 291-294 (2011) 573-578.

[53] Natureworks, Technology focus report: Blends of PLA with other thermoplastics, NatureWorks LLC, Minnetonka, MN, 2007.

[54] C.A. Bashur, R.D. Shaffer, L.A. Dahlgren, S.A. Guelcher, A.S. Goldstein, Effect of fiber diameter and alignment of electrospun polyurethane meshes on mesenchymal progenitor cells, Tissue Eng. Part A 15(9) (2009) 24352445.

[55] L. Moroni, R. Licht, J. de Boer, J.R. de Wijn, C.A. van Blitterswijk, Fiber diameter and texture of electrospun PEOT/PBT scaffolds influence human mesenchymal stem cell proliferation and morphology, and the release of incorporated compounds, Biomater. 27(28) (2006) 4911-4922.

[56] L.-X. Lü, Y.-Y. Wang, X. Mao, Z.-D. Xiao, N.-P. Huang, The effects of PHBV electrospun fibers with different diameters and orientations on growth behavior of bone-marrow-derived mesenchymal stem cells, Biomed. Mater. 7(1) (2012).

[57] S.H. Lim, H.-Q. Mao, Electrospun scaffolds for stem cell engineering, Adv. Drug Deliv. Rev. 61(12) (2009) 1084-1096.

[58] G.T. Christopherson, H. Song, H.-Q. Mao, The influence of fiber diameter of electrospun substrates on neural stem cell differentiation and proliferation, Biomater. 30 (2009)556-564.

[59] Y.-C. Kuo, S.-C. Hung, S.-h. Hsu. The effect of elastic biodegradable polyurethane electrospun nanofibers on the differentiation of mesenchymal stem cells, Colloids and Surfaces B: Biointerfaces 122 (2014) 414-422.

[60] T.L. McCarthy, C. Ji, Y. Chen, K.K. Kim, M. Imagawa, Y. Ito, M. Centrella, Runt domain factor (Runx)-dependent effects on CCAAT/enhancer-binding protein $\delta$ expression and activity in osteoblasts, J. Biol. Chem. 275(28) (2000) 21746-2153. 


\section{a) Bicomponent Multifilament

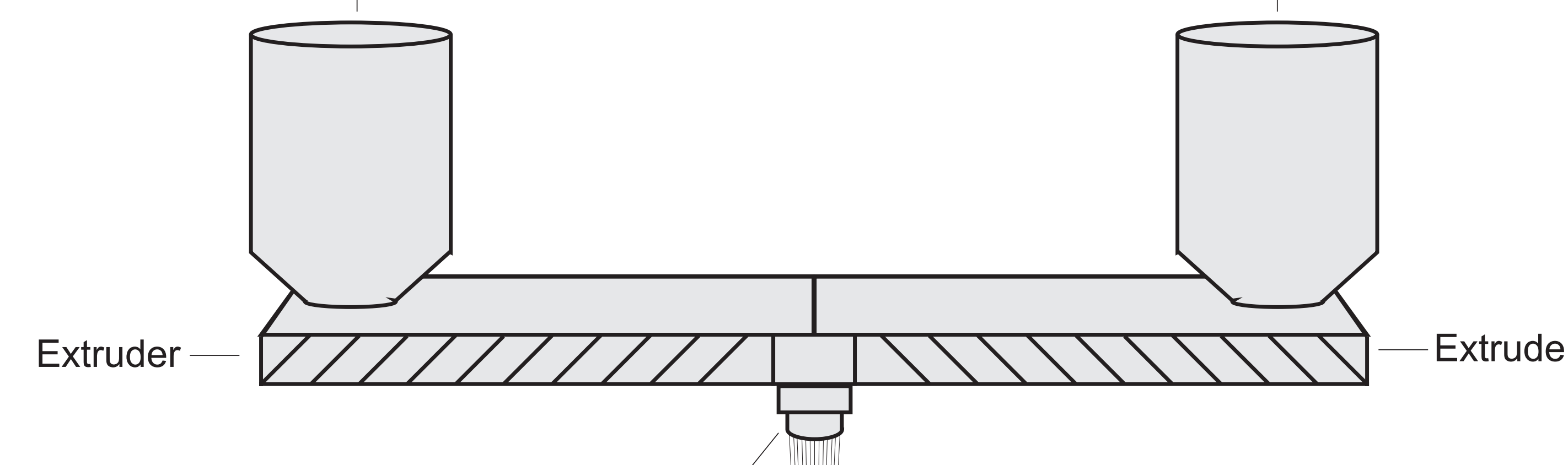

Extruder

Bicomponent

Spinnerette/Die

and Cutting

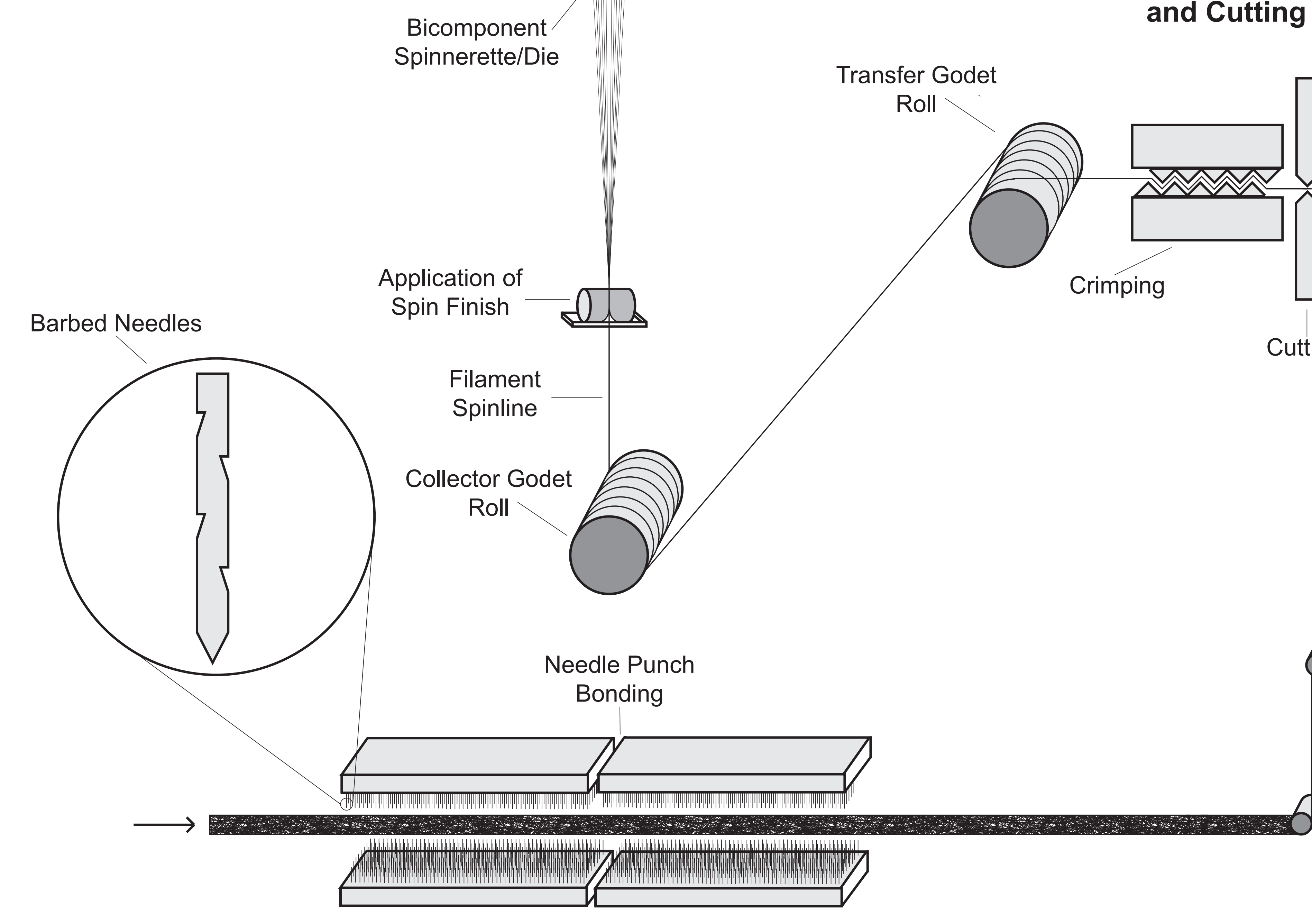

Feed Rolls $\underset{1 n}{2}$

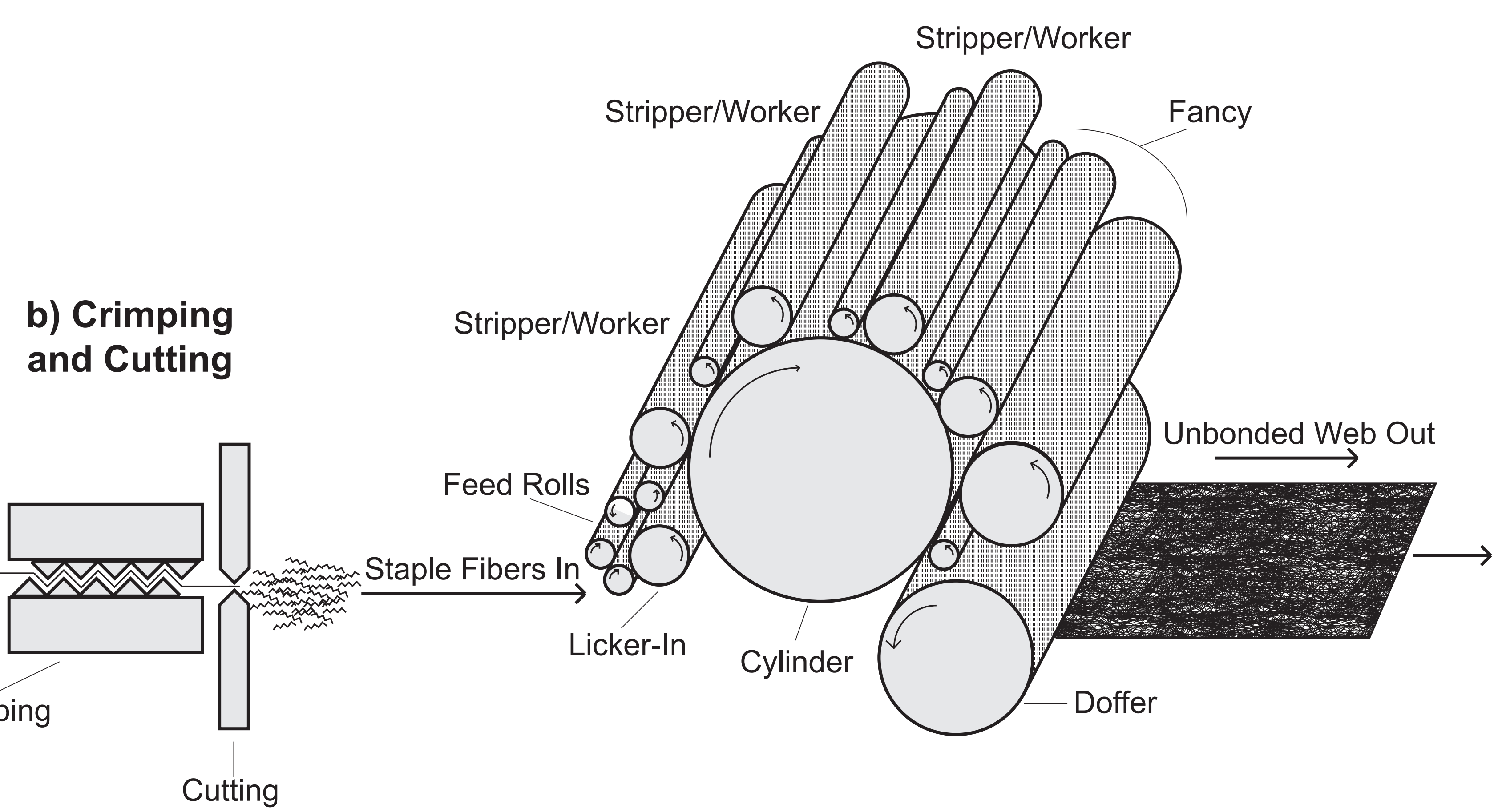

c) Carding

DI Water
Wash

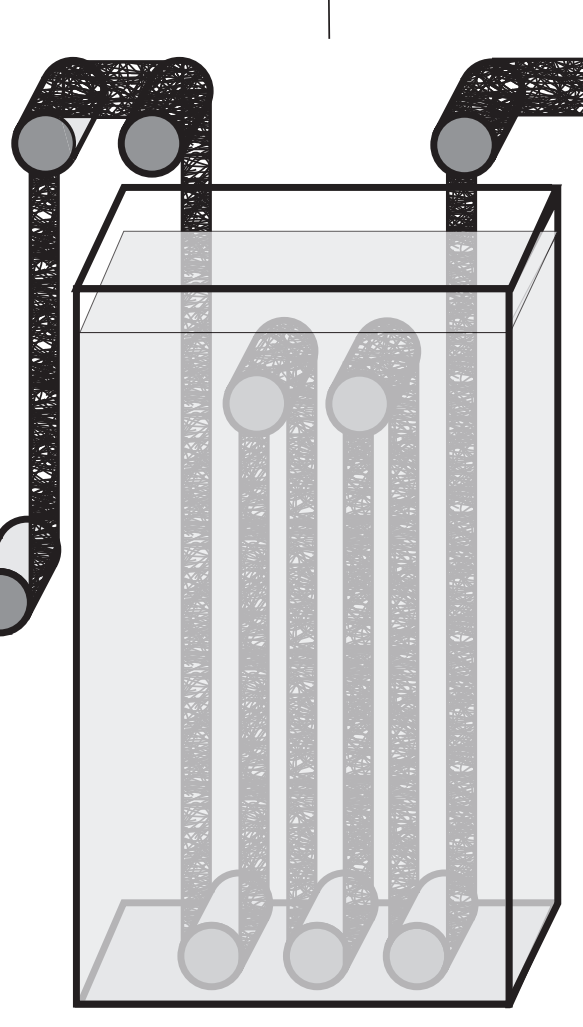

\section{e) Washing}


Figure 1. Schematic of gilled fiber multifilament spinning and carded scaffold fabrication. a) Bicomponent multifilament spinning: PLA and AQ55S polymer pellets are fed to separate extruders, melted, and forced through the bicomponent spinnerette/die. The spinnerette design directs the molten polymers through a series of specialized plates to form the winged cross section. Individual filaments are formed at each orifice and collected as a fiber bundle or spinline and wound around the collector godet roll via a vacuum gun (lurgi gun). Multifilaments are wound and collected on a bobbin or transferred via additional godet rolls for subsequent processing. b) Crimping and cutting: Fibers are crimped into a zig-zag pattern to facilitate transfer to carding rolls and cut into short (about $5 \mathrm{~cm}$ ) individual staple fibers. c) Carding: Staple fibers are converted to an unbonded fiberweb via a series of specialized combed rollers. d) Bonding: Web structure is locked into place via needle punching. Barbed needles snare and entangle fibers through the scaffold thickness. e) The AQ55S component is removed via washing in hot deionized water. Finally, the scaffold is dried in an oven followed by winding on a collector roll. Fabrication is depicted as a continuous process; scaffolds fabricated in this study were processed in batch operations (bicomponent filament spinning, crimping and cutting, carding, bonding, and washing). 


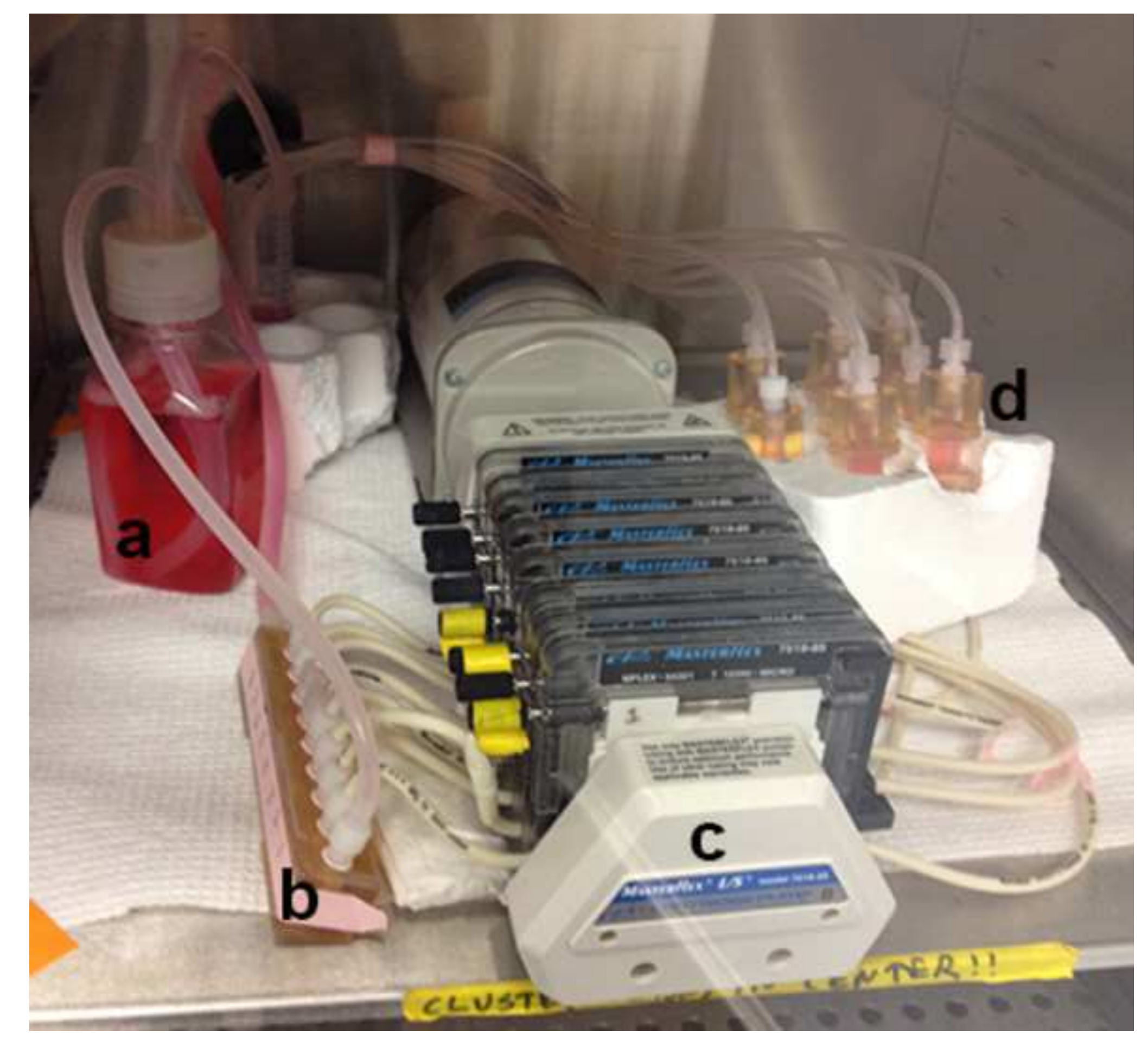
.

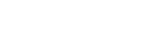
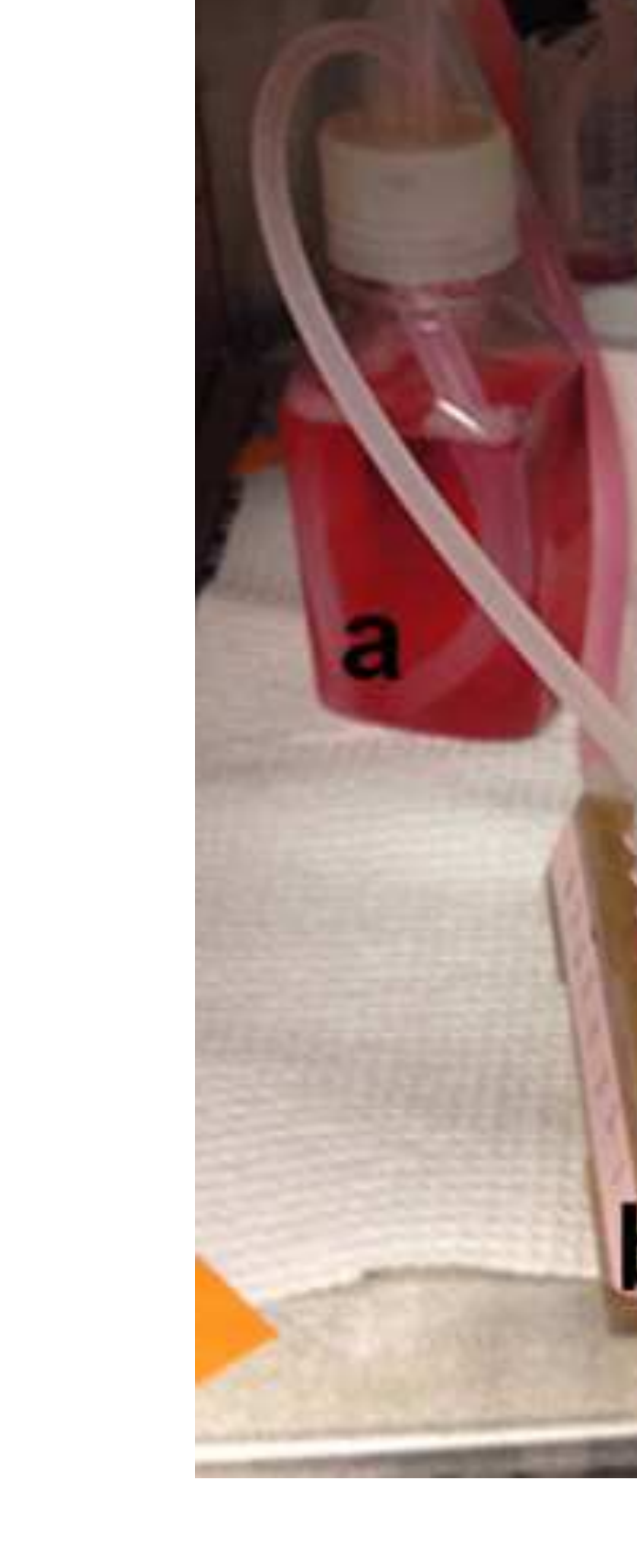
Figure 2. Pulsatile fluid flow (PFF) reactor setup. (a) Complete growth medium reservoir, (b) medium distribution manifold, (c) peristaltic pump, and (d) shear stress chambers containing scaffolds seeded with human adipose derived stem cells. No fluid leakage was observed during the experiment. Volumetric flow rates were validated for accuracy between chambers before application of PFF to confirm shear stress magnitudes of $0,3,6$, and 9 dynes $/ \mathrm{cm}^{2}$. 
Figure 3

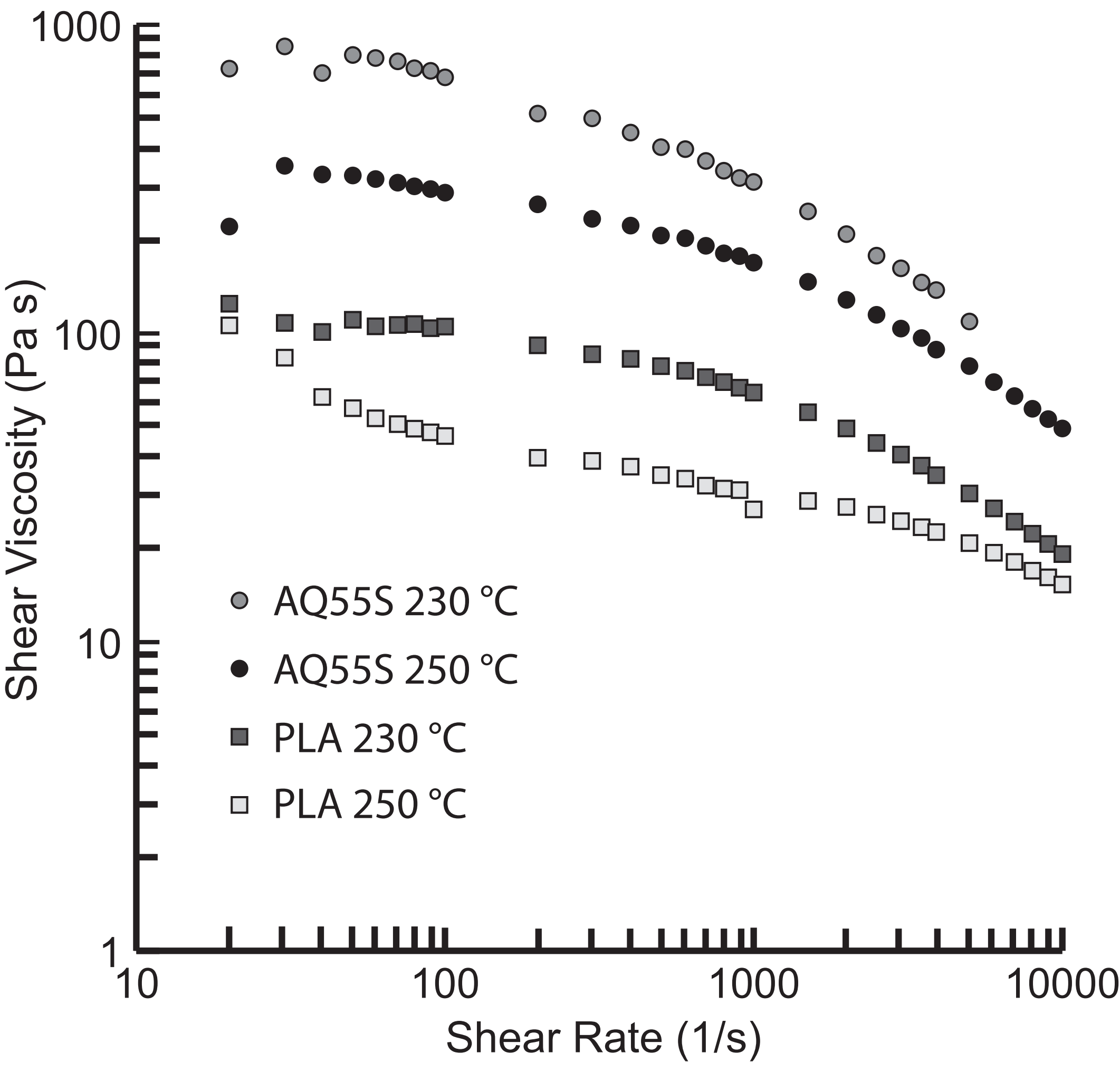


Figure 3. Shear viscosity (Pa s) versus shear rate (1/s) for pure PLA and AQ55S at 230 and $250^{\circ} \mathrm{C}$. AQ55S exhibited viscosities 2-6 times greater than pure PLA. 
Figure 4. Scanning electron microscopy images of scaffold surfaces at 500x magnification (top row) and fiber cross sections at 2000x (middle row) and 5000x (bottom row) magnification. A winged fiber cross section was observed for unwashed gilled fibers $\left(b_{2}\right.$ and $\left.c_{2}\right)$. Washing resulted in the formation of the gilled fiber morphology, consisting of a PLA sheath and finger like projections toward a hollow core $\left(b_{3}\right.$ and $\left.c_{3}\right)$. Scale bars represent $100 \mu \mathrm{m}$ (top row), $50 \mu \mathrm{m}$ (middle row), and $10 \mu \mathrm{m}$ (bottom row). 
Figure 5. Empirical calculation of gilled fiber density. Representative SEM image of gilled fiber cross section (a) and (b). Cross sectional image was converted to a threshold image using ImageJ software (c) and converted to an area map to determine hollow area as a percentage of total fiber cross sectional area (d). Scale bars represent $10 \mu \mathrm{m}$. 
Figure 6

2.0 PLA Control

$\square$ Gilled Unwashed

$\square$ Gilled Washed

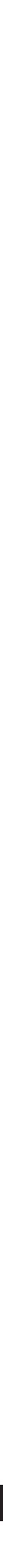

0.0 
Figure 6. Brunauer-Emmett-Teller surface area analysis of cell seeded scaffolds. The washing procedure and subsequent formation of gilled fiber scaffolds resulted in specific surface area of $1.677 \mathrm{~m}^{2} / \mathrm{g}$, compared to $0.104 \mathrm{~m}^{2} / \mathrm{g}$ for unwashed scaffolds, representing an over $1500 \%$ increase. 
Figure 7. Representative engineering stress strain curves for acellular scaffolds (a), and resultant peak load (b). Removal of the AQ55S component led to an increase in peak load for gilled fiber scaffolds compared to unwashed gilled scaffolds, however this increase was not significant. 
50

PLA Control

$\square$ Gilled

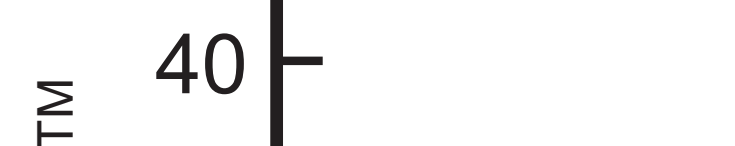

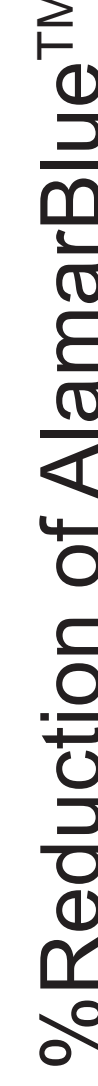

30

$-$

20

ae

bce

b

bce bc

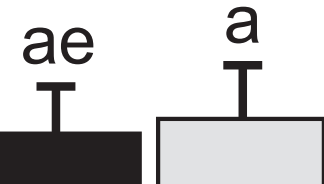

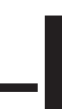

T
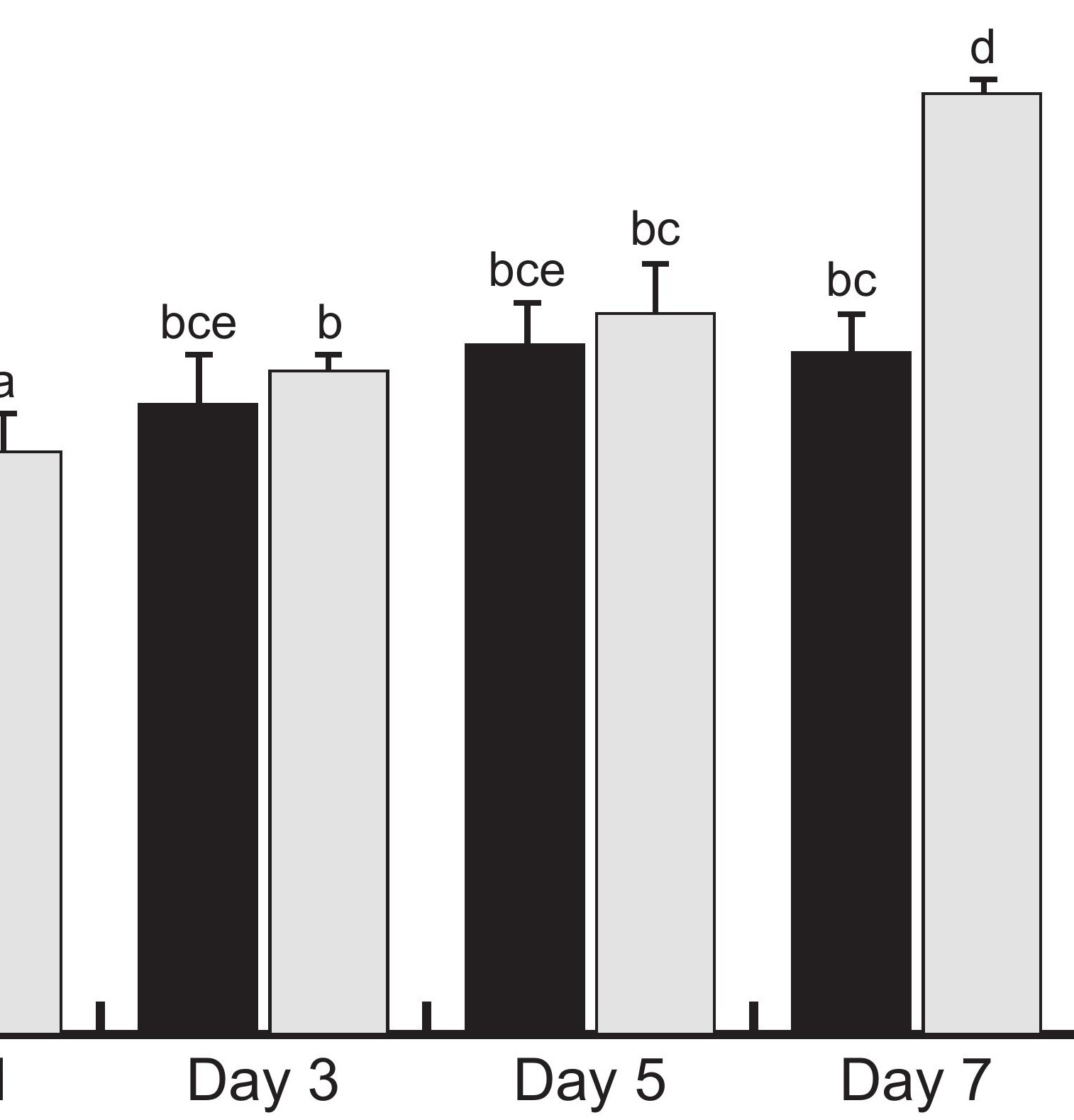

Day 3

Day 7 
Figure 8. AlamarBlue ${ }^{\mathrm{TM}}$ cellular proliferation on PLA control and gilled scaffolds. There were no significant differences between scaffold types observed over the first five days in culture, however a significant increase in cellular proliferation was observed on gilled scaffolds on day seven compared to PLA control scaffolds. Different letters represent statistical significance $(p<0.05)$. Error bars represent standard error of the mean. 
a

Day 1

Day 3
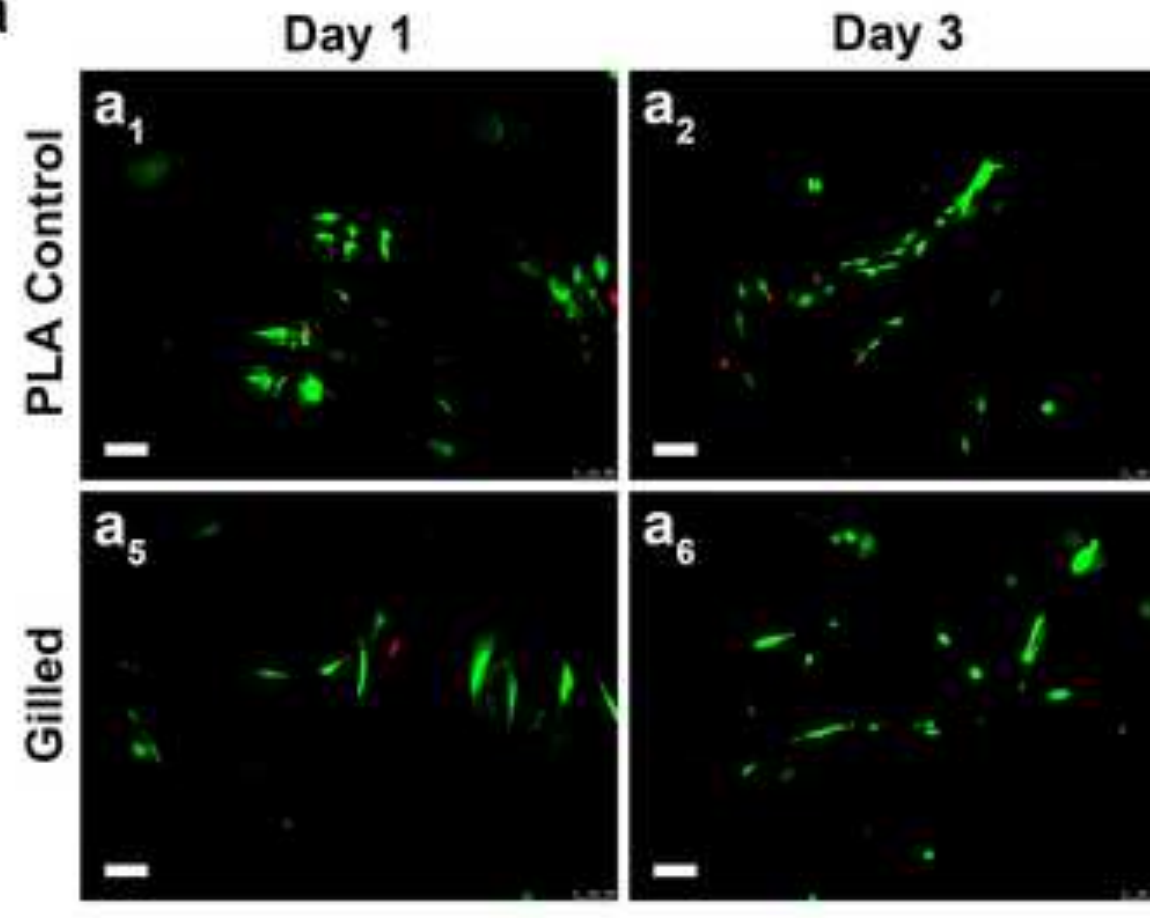

Day 5

Day 7

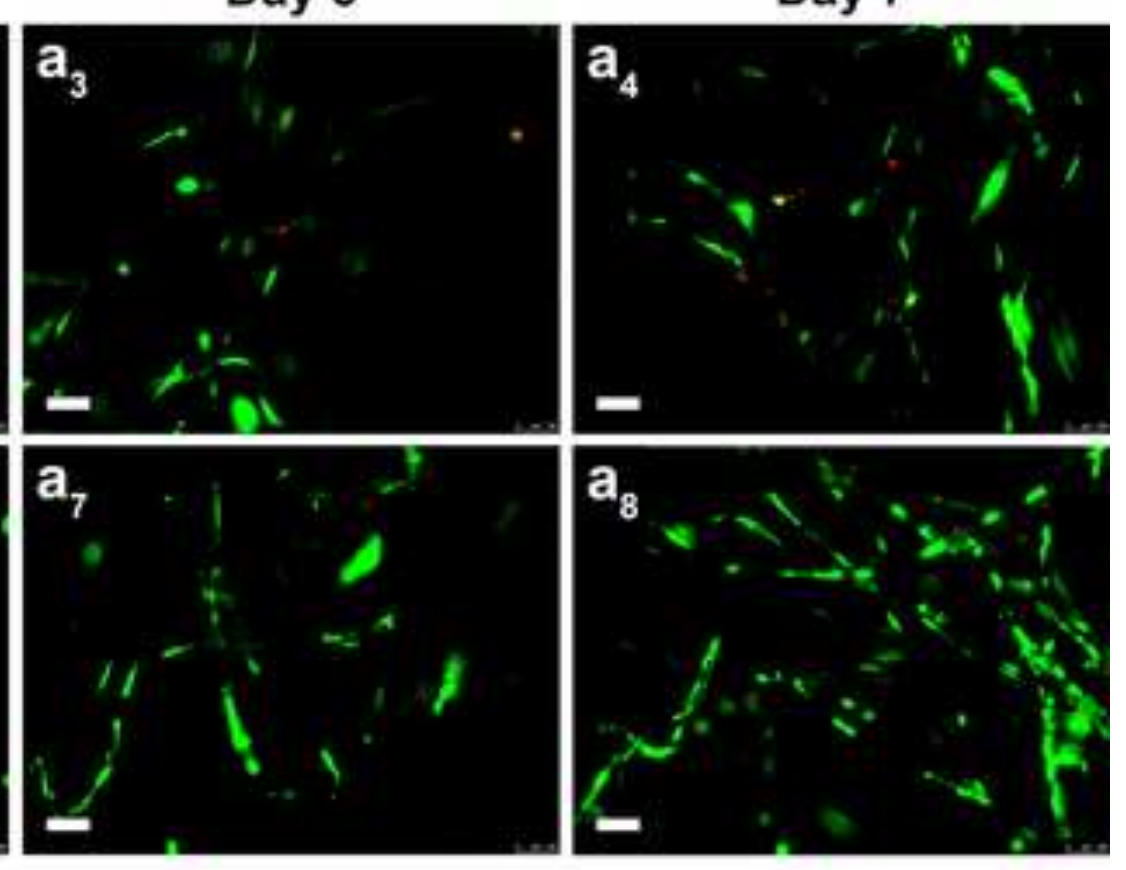

b
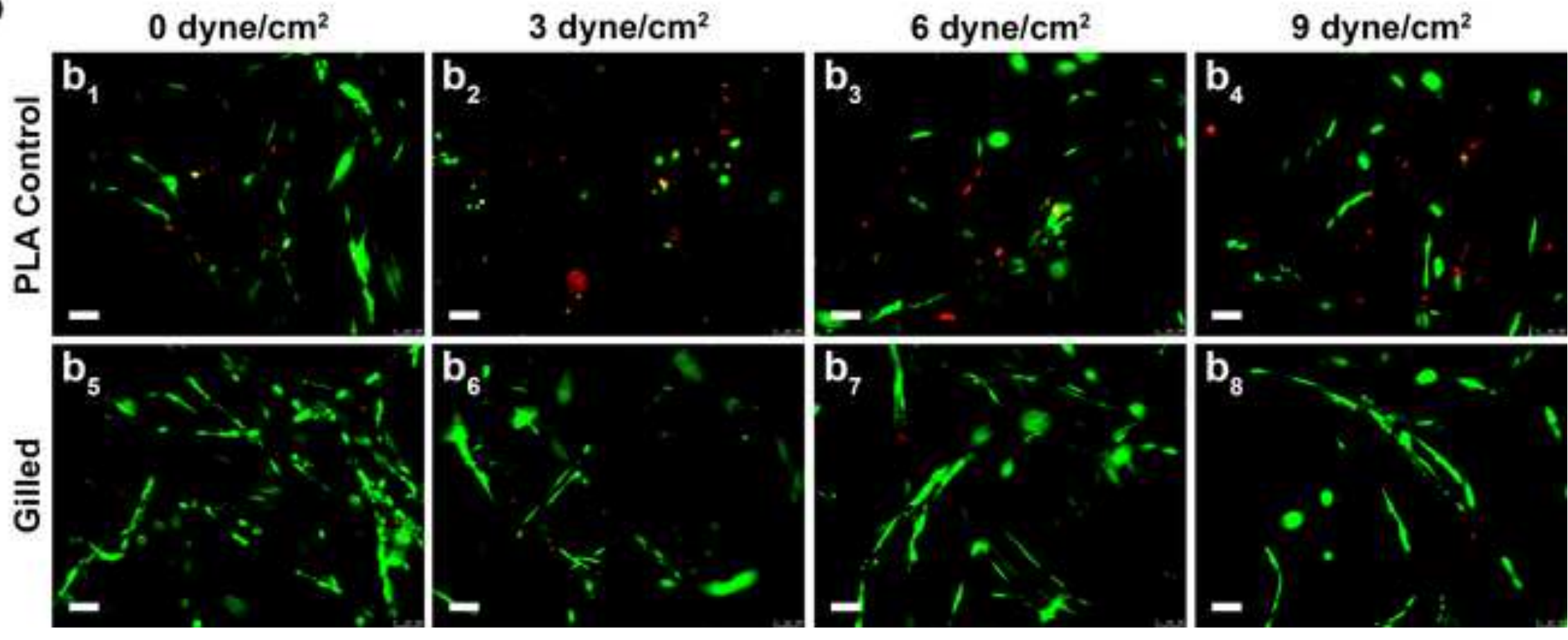
Figure 9. Live/Dead viability of human adipose derived stem cells (hASC). Live cells stained green, dead cells stained red. (a) Human ASC viability over the seven day expansion period. Little difference was observed in the number of viable cells over the first five days between scaffold types $\left(a_{1}-a_{3}\right.$ and $\left.a_{5}-a_{7}\right)$, however gilled scaffolds appeared to exhibit a greater number of live cells on day seven $\left(a_{4}\right.$ versus $\left.a_{8}\right)$. A greater number of dead cells were observed on PLA control scaffolds compared to gilled scaffolds at each time point. (b) Human ASC viability was determined immediately after application of one hour pulsatile fluid flow (PFF). A greater number of viable cells were observed on gilled scaffolds for all shear stress magnitudes compared to PLA control scaffolds. Further a greater number of dead cells were observed for all shear stress magnitudes on PLA control scaffolds compared to gilled scaffolds $\left(b_{2}-b_{4}\right.$ compared to $\left.b_{6}-b_{8}\right)$. 


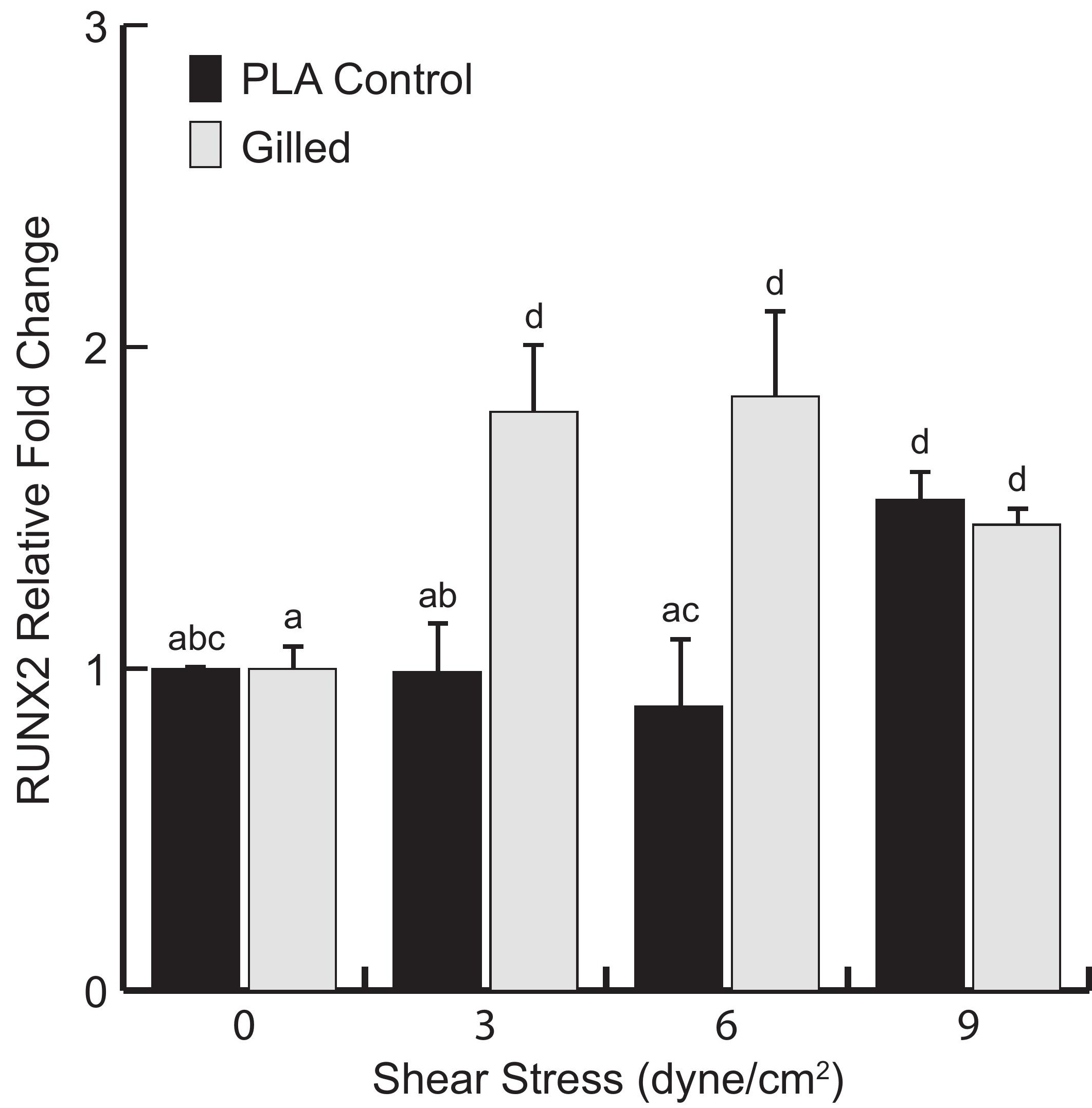


Figure 10. Real time reverse transcriptase polymerase chain reaction (RTqPCR) results. Fold change expression of runt related transcription factor 2 (RUNX2) normalized to hypoxanthine phosphoribosyltransferase 1 for each scaffold at each pulsatile fluid flow (PFF) magnitude. No statistically significant differences were observed between scaffold types on unstimulated controls (PFF $=0$ dyne $/ \mathrm{cm}^{2}$ ); however hASC seeded on gilled scaffolds exhibited a significant increase in RUNX2 expression at shear stress magnitudes of 3 and 6 dyne/cm 2 . There was no significant difference between scaffold types at $9 \mathrm{dyne} / \mathrm{cm}^{2}$; however each scaffold type exhibited significantly increased RUNX2 mRNA expression compared to their respective unstimulated controls. 
